\title{
Anti-vascular endothelial growth factor for macular edema secondary to central retinal vein occlusion
}

\author{
Tasanee Braithwaite ${ }^{1}$, Afshan A Nanji ${ }^{2}$, and Paul B Greenberg ${ }^{3}$ \\ ${ }^{1}$ Moorfields Eye Hospital NHS Foundation Trust, London, UK \\ ${ }^{2}$ Wilmer Eye Institute, Johns Hopkins University School of Medicine, Baltimore, Maryland, USA \\ ${ }^{3}$ Division of Ophthalmology, Warren Alpert Medical School of Brown University, Providence, \\ Rhode Island, USA
}

\begin{abstract}
Background-Central retinal vein occlusion (CRVO) is a common retinal vascular disorder in which macular edema (ME) may develop, with a consequent reduction in visual acuity. The visual prognosis in CRVO-ME is poor in a substantial proportion of patients, especially those with the ischemic subtype, and until recently there has been no treatment of proven benefit. Macular grid laser treatment is ineffective, and whilst a few recent randomized controlled trials (RCTs) suggest
\end{abstract}

Copyright @ 2010 The Cochrane Collaboration. Published by John Wiley \& Sons, Ltd.

Contact address: Tasanee Braithwaite, Moorfields Eye Hospital NHS Foundation Trust, 162 City Road, London, EC1V 2PD, UK. tasaneebraithwaite@gmail.com.

NOTES

PG is also affiliated with the Section of Ophthalmology, VA Medical Center, Providence, RI, USA 02908.

CONTRIBUTIONS OF AUTHORS

Conceiving the review: $\mathrm{PG}$

Designing the review: TB, AN

Co-ordinating the review: TB

Data collection for the review

- Designing electronic search strategies: TB, AN, CEVG Trials Search Co-ordinator

- Undertaking manual searches: TB, AN

- Screening search results: TB, AN

- Organizing retrieval of papers: TB, AN

- Screening retrieved papers against inclusion criteria: TB, AN

- Appraising quality of papers: TB, AN

- Extracting data from papers: TB, AN

- Writing to authors of papers for additional information: TB

- Providing additional data about papers: TB, AN

- Obtaining and screening data on unpublished studies: TB, AN

Data management for the review

- Entering data into RevMan: TB, AN

- Analysis of data: TB, AN

Interpretation of data

- Providing a methodological perspective: TB, AN, PG

- Providing a clinical perspective: TB, PG, AN

- Providing a policy perspective: TB, PG

- Providing a consumer perspective: TB, AN, PG

Writing the review: TB

Providing general advice on the review: PG, TB, AN

Performing previous work that was the foundation of the current study: PG

DECLARATIONS OF INTEREST

PG received consulting fees from (OSI) Eyetech Pharmaceuticals and is currently a co-investigator of a clinical trial funded by Genentech. 
short-term gains in visual acuity with intravitreal steroids for patients with non-ischemic CRVO$\mathrm{ME}$, there is no established treatment for ischemic CRVO-ME. Anti-vascular endothelial growth factor (anti-VEGF) agents have been used to treat ME resulting from a variety of causes and may represent a treatment option for CRVO-ME.

Objectives-To investigate the effectiveness and safety of intravitreal anti-VEGF agents in the treatment of CRVO-ME.

Search strategy-We searched the Cochrane Central Register of Controlled Trials (CENTRAL) (which contains the Cochrane Eyes and Vision Group Trials Register) (The Cochrane Library 2010, Issue 8), MEDLINE (January 1950 to August 2010), EMBASE (January 1980 to August 2010), Latin American and Caribbean Health Sciences Literature Database (LILACS) (January 1982 to August 2010), Cumulative Index to Nursing and Allied Health Literature (CINAHL) (January 1937 to August 2010), OpenSIGLE (January 1950 to August 2010), the metaRegister of Controlled Trials ( $m$ RCT) (www.controlled-trials.com) and ClinicalTrials.gov (www.clinicaltrials.gov). There were no language or date restrictions in the search for trials. The electronic databases were last searched on 10 August 2010.

Selection criteria-We considered RCTs that compared intravitreal anti-VEGF agents of any dose or duration to sham injection or no treatment. We focused on studies that included individuals of any age or gender with unilateral or bilateral disease and a minimum of six months follow up. Secondarily, we considered non-randomized studies with the same criteria, but did not conduct a separate electronic search for these.

Data collection and analysis-Two review authors independently assessed trial quality and extracted data.

Main results-We found two RCTs that met the inclusion criteria after independent and duplicate review of the search results. These RCTs utilized different anti-VEGF agents which cannot be assumed to be directly comparable. We, therefore, performed no meta-analysis. Evidence from these trials and from other non-randomized case series is summarized in this review.

Authors' conclusions-Ranibizumab and pegaptanib sodium have shown promise in the short-term treatment of non-ischemic CRVO-ME. However, effectiveness and safety data from larger RCTs with follow up beyond six months are not yet available. There are no RCT data on anti-VEGF agents in ischemic CRVO-ME. The use of anti-VEGF agents to treat this condition therefore remains experimental.

\section{PLAIN LANGUAGE SUMMARY}

\section{Anti-vascular endothelial growth factor for macular edema secondary to central vein occlusion}

Central retinal vein occlusion (CRVO) is thought to affect between one and four people per thousand at any one time, and is associated with increasing age, high blood pressure, diabetes, glaucoma and various disorders of the blood. It frequently causes sudden painless vision loss in one eye, although sometimes the vision loss may be minimal. If the vein blockage leads to inadequate oxygen delivery to the sensitive retinal tissue, the CRVO is considered to be of the 'non-perfused' or 'ischemic' subtype. More commonly, blood flow 
and oxygen delivery are restored following the vein blockage and the CRVO is considered to be of the 'perfused' or 'non-ischemic' subtype, which has a better visual outcome. Various other complications may develop over hours, days, weeks or months. These include macular edema (ME), in which fluid collects within the retina and causes reduction in vision. Until recently there has been no evidence-based treatment for this condition and many potential treatments, including laser, have been found to be ineffective. Recent studies suggest that an injection or implant of steroids in the eye may be of at least short-term benefit to patients with the perfused subtype of the condition. However, steroids are associated with significant side effects and there is currently no evidence that the benefit is sustained, or that patients with the non-perfused subtype of CRVO benefit from this treatment. Anti-vascular endothelial growth factor (anti-VEGF) agents have been used successfully to treat patients with other retinal vascular disorders, including several conditions associated with ME. Whilst anti-VEGF treatment appears to be associated with improved vision in a proportion of patients with perfused CRVO-ME, there are currently no well-designed studies with a sufficient follow-up time in the literature to allow a conclusion about their medium and long-term effectiveness and safety to be drawn. The outcomes of several trials with follow up exceeding one year are keenly awaited, and the use of antiVEGF agents for CRVO-ME remains experimental.

\section{BACKGROUND}

\section{Description of the condition}

Central retinal vein occlusion (CRVO) is a common retinal vascular disorder in which macular edema (ME), including the cystoid type, may develop with a consequent reduction in visual acuity (Guex-Crosier 1999; Hayreh 1983). Both the burden of CRVO-ME in the population and the incidence of ME following CRVO are unknown (McIntosh 2010). There are also only limited population-based data on the burden of CRVO, which may not be generalizable; the available prevalence estimates of $0.4 \%$ (Mitchell 1996) and $0.1 \%$ (Klein 2000) and the 15-year cumulative incidence of $0.5 \%$ (Klein 2008) are derived from surveys of white adults aged over 40 years in the United States and Australia. Cystoid macular edema is characterized by the collection of fluid in intercellular spaces within the outer plexiform layer of the retina and results from the breakdown of the capillary endothelium blood-retinal barrier and leakage of fluid from the vasculature (Guex-Crosier 1999; Vinores 1999). This process is promoted by vascular endothelial growth factor (VEGF) (Vinores 1999) and the aqueous concentration of VEGF has been found to be significantly elevated in patients with CRVO-ME compared to controls (Funk 2009). Furthermore, there is a significant inverse association between duration since onset of CRVO-ME and the aqueous VEGF concentration (Funk 2009). Macular edema can be visualized with slit-lamp biomicroscopy and its thickness and pattern of distribution can be investigated and quantified using optical coherence tomography (OCT) (Catier 2005; Hee 1995).

Central retinal vein occlusion is currently classified into two subtypes, 'perfused' or 'nonischemic' and 'non-perfused' or 'ischemic', although it is unlikely that the disease process is binary. One definition of ischemic CRVO is the presence of a relative afferent pupillary defect in the affected eye, which has been found to be a sensitive and specific sign (Servais 
1986). Another definition is based on the area of capillary dropout on fundus fluorescein angiography (FFA) (CVOS Group 1997; Hayreh 2005; Quinlan 1990), with more than 10 disc areas of dropout indicating ischemic CRVO (CVOS Group 1997). At present there is a paucity of population-level data on the prevalence and incidence of ischemic versus nonischemic CRVO-ME, but the distinction is important because their natural history differs (Hayreh 1983; Hayreh 1994). The ischemic subtype of CRVO accounts for approximately $20 \%$ of acute presentations (Hayreh 1983; Hayreh 1994). Ischemic CRVO is associated with a poor visual prognosis (CVOS Group 1997; Hayreh 2001). Visual morbidity, including blindness, results from persistent macular edema, macular ischemias, ocular neovascularization or secondary glaucoma (Campochiaro 2008). The non-ischemic type has a better visual prognosis, but may convert to the ischemic type in an estimated one-third of cases within three years, and conversion is most frequent in the initial four months (CVOS Group 1997). After developing a CRVO there is a $1 \%$ chance per year of a retinal vein occlusion in the fellow eye (CVOS Group 1997).

Presenting visual acuity is a key predictor of visual outcome at three years (CVOS Group 1997): $65 \%$ of patients with presenting visual acuity better than or equal to $6 / 12(20 / 40)$ maintain this level of vision; those with presenting visual acuity $6 / 12$ to $6 / 60(20 / 40$ to 20/200) have a variable prognosis with $19 \%$ improving to better than $6 / 15$ (20/50), 44\% showing no improvement and 37\% worsening to less than $6 / 60$ (20/200); whilst $80 \%$ of those with vision less than $6 / 60(20 / 200)$ at presentation have no visual improvement.

The prevalence of CRVO increases with age and in the United States reaches $0.4 \%$ in those 75 years and over (Klein 2000) with no gender difference (Klein 2008). No ethnic differences in prevalence have been identified to date, but population-based surveys on mixed ethnicity populations from regions beyond the United States and Australia are lacking. There is a paucity of data on risk factors for developing ME following CRVO (Hayreh 1994).

At present, there is no established intervention for the treatment of CRVO-ME. Various medical and surgical interventions have been tried, including argon laser panretinal photocoagulation (Hayreh 1990), macular grid photocoagulation (CVOS Group 1995), tissue plasminogen activator (Everett 2006), oral pentoxifylline (Park 2007), hyperbaric oxygen therapy (Wright 2007), radial optic neurotomy (Arevalo 2008; Hasselbach 2007; Opremcak 2006; Zambarakji 2005) and pars plana vitrectomy with internal limiting membrane peeling (DeCroos 2009; Park 2010; Raszewska-Steglinska 2009), but these have not been successful. More recently, an RCT comparing laser-induced chorioretinal venous anastomosis to sham treatment in adults with non-ischemic CRVO-ME of three to twelve months duration demonstrated moderate efficacy, especially in the $76 \%$ who developed a functioning anastomosis following laser treatment, and the visual acuity advantage compared to control was maintained at 18 months (McAllister 2010). However, 18\% in the treatment arm developed neovascularization at the treatment site and $9 \%$ required vitrectomy surgery for macular traction or non-resolving vitreous hemorrhage (McAllister 2010). 
Two recent RCTs on corticosteroids for CRVO-ME have also demonstrated promise, but there are concerns about the incidence of complications (Gewaily 2009). Firstly, the Standard Care vs. Corticosteroid for Retinal Vein Occlusion trial (SCORE 2009) treated participants with non-ischemic CRVO-ME with either 1mg or 4mg intravitreal triamcinolone (IVTA) injections repeated every four months, or observation alone. Both treatment doses were associated with a five times increase in the odds of achieving a 15 letter gain in visual acuity at 12 months $(\mathrm{P}=0.001)$. However, $35 \%$ of patients treated with $4 \mathrm{mg}$, and $20 \%$ of patients treated with $1 \mathrm{mg}$, required intraocular pressure lowering treatment by 12 months compared to $8 \%$ in the observation group (SCORE 2009). Similarly, at 12 months there was new lens opacity, or progression of existing lens opacity, in $33 \%$ of the $4 \mathrm{mg}$ group and $26 \%$ of the $1 \mathrm{mg}$ group, compared to $18 \%$ of the observation group (SCORE 2009).Secondly, the Ozurdex trial compared a single dexamethasone implant, at a dose of $0.7 \mathrm{mg}$ or $0.35 \mathrm{mg}$, to a sham implant, in adults with branch retinal vein occlusion (BRVO)-ME and CRVO-ME of six weeks to nine months duration (ischemic versus nonischemic status not specified) (Haller 2010). The percentage of eyes with CRVO-ME achieving a 15 letter improvement in visual acuity was significantly higher in both Ozurdex groups at day 30 and day 60 than in the sham group $(\mathrm{P}<0.001)$, with the maximal effect at day 60 . However, by days 90 and 180 there was no significant difference between groups (Haller 2010). The incidence of ocular adverse events was not reported for CRVO-ME separately, but did not differ significantly between the $0.35 \mathrm{mg}$ and $0.7 \mathrm{mg}$ dose groups. In both groups there was a higher incidence of ocular hypertension at day $60(\mathrm{P}<0.002)$, and by day 180 approximately $24 \%$ of patients with dexamethasone implants required IOPlowering medication, and five patients required a surgical/laser procedure to reduce IOP (Haller 2010). There was also a significant increase in anterior chamber activity in the 0.35 $\mathrm{mg}(\mathrm{P}=0.007)$ and $0.7 \mathrm{mg}(\mathrm{P}=0.03)$ treatment groups compared to sham $(\mathrm{P}=0.03)$, but no significant increase in the risk of incident cataract at 180 days (Haller 2010).

\section{Description of the intervention}

Monoclonal antibodies against VEGF were first developed as an intravenous treatment for metastatic colorectal cancer (Homsi 2007; Los 2007). The first drug licensed for this purpose was bevacizumab (Avastin $\left.{ }^{\circledR}\right)$, which received Food and Drug Administration (FDA) approval in February 2004 (Genetech/Roche 2009b). Bevacizumab is a 149kDa recombinant humanized monoclonal whole immunoglobulin G1 antibody that binds to VEGF and blocks the binding of VEGF to receptors (Flt-1 and KDR) on endothelial cells (Genentech 2009). Pegaptanib sodium (Macugen $®$ ) is a 50kDa aptamer; a pegylated modified oligonucleotide, which adopts a three-dimensional configuration in vivo which allows it to bind to extracellular VEGF-165 and antagonize its biological effects (Eyetech 2008; Gragoudas 2004). It was approved by the FDA in 2004 for use in neovascular agerelated macular degeneration (Eyetech 2008). Ranibizumab (Lucentis ${ }^{\circledR}$ ) was subsequently approved by the FDA for the treatment of neovascular age-related macular degeneration in June 2006 (Genetech/Roche 2009a). Ranibizumab is a 48kDa recombinant humanized monoclonal immunoglobulin G1 antibody fragment (kappa isotype) that binds to the receptors of biologically active VEGF-A, including VEGF-110. This blocks the binding of VEGF-A to VEGFR1 and VEGFR2 receptors on endothelial cells (Genentech 2008). 
The pharmacokinetics of $1.25 \mathrm{mg}$ bevacizumab and $0.5 \mathrm{mg}$ ranibizumab intravitreal injections have been investigated in an experimental rabbit model (Bakri 2007a; Bakri 2007b). The vitreous concentration of both drugs declined in a monoexponential function, with a half-life of 4.32 days for bevacizumab, and 2.88 days for ranibizumab. At 30 days both drugs persisted in the vitreous, at a concentration of $>0.1 \mu \mathrm{g} / \mathrm{ml}$ for ranibizumab versus $>10 \mu \mathrm{g} / \mathrm{ml}$ for bevacizumab. No ranibizumab was detected in the fellow eye or serum, whilst a peak serum concentration of bevacizumab of $3.3 \mu \mathrm{g} / \mathrm{ml}$ was reached at eight days, with a half-life of 6.86 days, and very low concentrations $(\mathrm{ng} / \mathrm{ml})$ were detected in the fellow eye throughout the 29-day study. The aqueous half-life of a single $1.5 \mathrm{mg}$ intravitreal injection of bevacizumab has also been studied in humans with various causes of ME and has been found to be approximately 9.8 days (Krohne 2008). Patients with CRVO demonstrate moderate variability in the aqueous concentration of ranibizumab measured one month after a first intravitreal injection of $0.3 \mathrm{mg}$ or $0.5 \mathrm{mg}$, but measurements one month following subsequent injections are highly correlated for a given patient (Campochiaro 2009).

More recently, the anti-VEGF agents have demonstrated promise in treating ME secondary to CRVO in retrospective and prospective case series (Costa 2007; Iturralde 2006; Pai 2007; Schaal 2007; Stahl 2007) and in a randomized trial comparing different doses (Campochiaro 2008). However, none are FDA approved for use in CRVO-ME.

\section{How the intervention might work}

Vascular endothelial growth factor is a cytokine that promotes vascular leakage. It has been observed that transgenic mice over-expressing VEGF in the photoreceptors exhibited bloodretina barrier failure (Vinores 1999). Another study observed that injecting VEGF intravitreally induces a time and dose-dependent breakdown of the blood-aqueous and blood-retinal barriers in a rabbit model, with maximal vascular leakage occurring 48 hours after injection (Edelman 2005). Animal and human studies have identified that the expression of VEGF mRNA is significantly up-regulated in regions of ischemic retina of various causes, including CRVO (Pe'er 1995; Pe'er 1998; Shima 1996). Furthermore, the concentration of VEGF in human aqueous demonstrates close temporal correlation with the course of neovascularization and permeability in CRVO, and injecting anti-VEGF antibodies inhibits VEGF-driven neovascularization both in vitro and in vivo (Adamis 1996; Aiello 1995; Boyd 2002). Vascular endothelial growth factor has also been shown to be a critical stimulus in the pathogenesis of ME secondary to diabetes (Nguyen 2006).

\section{Why it is important to do this review}

The visual prognosis in CRVO-ME is poor in a substantial proportion of patients, especially those with the ischemic subtype, and until recently there has been no treatment of proven benefit (Everett 2006; Hayreh 2003; Prisco 2002). Clinicians internationally are increasingly using anti-VEGF agents off-label for the treatment of CRVO-ME, based on anecdotal experience and a growing volume of published case series. Numerous RCTs investigating anti-VEGF for the treatment of CRVO-ME are in progress and the outcomes of these are anticipated in the near future. This systematic review was therefore designed to investigate the effectiveness and safety of anti-VEGF agents for the treatment of CRVO-ME. 


\section{OBJECTIVES}

The aim of this review was to investigate the effectiveness and safety of anti-VEGF therapies for the treatment of ME secondary to CRVO.

\section{METHODS}

\section{Criteria for considering studies for this review}

Types of studies-This review was designed to include all RCTs, or quasi-RCTs, in which quasi-random methods of allocation, such as alternation, date of birth or medical record number, were used.

Types of participants-We searched for trials involving participants of all ages who had unilateral or bilateral ME secondary to CRVO.

Types of interventions-We searched for trials in which anti-VEGF treatment was compared placebo or no treatment, and trials that investigated dosage and duration of treatment. We excluded studies in which anti-VEGF agents were only compared to, or used in combination with other agents.

\section{Types of outcome measures}

Primary outcomes: The primary outcome for this review was the proportion of patients with an improvement from baseline in best-corrected visual acuity (BCVA) of greater than or equal to 15 letters (3 lines) on the Early Treatment in Diabetic Retinopathy Study (ETDRS) Chart at four meters, after six months of follow up and any additional follow up times. A gain of 15 letters represents a doubling of the visual angle, and whilst this binary cut-off considerably exceeds the amount of change required to have a high degree of certainty that the observed change is real, even in the presence of poor vision, it has been the standard primary outcome measure for evaluating the efficacy of treatments for retinal diseases for more than a decade (Beck 2007).

Secondary outcomes: We included the following secondary outcomes.

1. Mean visual acuity change at six months and any additional follow-up times reported.

2. The proportion of patients with a loss of 15 or more letters (ETDRS) compared to baseline, at six months and any additional follow-up times.

3. Objective assessment of ME regression measured by mean change in central retinal thickness on ocular coherence tomography (OCT).

4. The number and type of complications.

5. The number of additional interventions administered.

Adverse outcomes-We searched for any ocular or systemic adverse outcomes reported in the trials. We specifically aimed to report the proportion of patients experiencing rebound 
ME, subconjunctival hemorrhage, retinal tears, retinal detachment, ocular inflammation, endophthalmitis, thromboembolic events, ocular hypertension, glaucoma and cataract.

Economic data-We reported any cost-benefit data included in the primary studies.

Quality of life data-We reported any data relating to impact on quality of life or daily functioning included in the primary studies.

\section{Search methods for identification of studies}

Electronic searches-We searched the Cochrane Central Register of Controlled Trials (CENTRAL) (which contains the Cochrane Eyes and Vision Group Trials Register) (The Cochrane Library 2010, Issue 8), MEDLINE (January 1950 to August 2010), EMBASE (January 1980 to August 2010), Latin American and Caribbean Health Sciences Literature Database (LILACS) (January 1982 to August 2010), Cumulative Index to Nursing and Allied Health Literature (CINAHL) (January 1937 to August 2010), OpenSIGLE (January 1950 to August 2010), the metaRegister of Controlled Trials ( $m$ RCT) (www.controlledtrials.com) and ClinicalTrials.gov (www.clinicaltrials.gov). There were no language or date restrictions in the search for trials. The electronic databases were last searched on 10 August 2010.

See: Appendices for details of search strategies for CENTRAL (Appendix 1), MEDLINE (Appendix 2), EMBASE (Appendix 3), LILACS (Appendix 4), CINAHL (Appendix 5), OpenSIGLE, $m$ RCT (Appendix 6) and ClinicalTrials.gov (Appendix 8).

Searching other resources-We manually searched references of included studies and used the Science Citation Index to identify additional studies citing trials.

\section{Data collection and analysis}

Selection of studies-Two review authors independently screened the titles and abstracts resulting from the electronic and manual searches. We classified abstracts as relevant, potentially relevant or not relevant for this review. We obtained full-text copies of articles for those abstracts that were designated relevant or potentially relevant. Two review authors independently assessed each article and determined whether to definitely include, definitely exclude or record each trial as unclear. We documented agreement between review authors and resolved discrepancies by consensus. For any studies classified as unclear we contacted the authors in an attempt to include or exclude the study from the review. We reported any studies that were definitely excluded.

Data extraction and management-We extracted the following participant and trial characteristics and reported them in a table format.

1. Methodology (group size, randomization and blinding (masking).

2. Participant characteristics (gender, age, type of CRVO and diagnostic criteria used, baseline visual acuity, OCT-determined thickness of ME). 
3. Intervention (agent, dose, timing of first dose in relation to diagnosis, delivery route, frequency and treatment length).

4. Primary and secondary outcomes (proportion with 15 letter gain in visual acuity at six months, proportion with 15 letter loss in visual acuity at six months, mean difference in visual acuity at six months compared to baseline, central macular thickness, adverse events and complications, and outcomes at longer follow-up intervals).

5. Additional data (economic, quality of life and visual functioning data).

6. Treatment compliance and losses to follow up.

Two review authors independently extracted the data using a form developed by the Cochrane Eyes and Vision Group. We contacted trial authors for more information if data were missing or difficult to interpret. We resolved any discrepancies between the two review authors by discussion and consensus. One review author entered the data into Review Manager 5 (RevMan 2008) and the second author checked the entered data for any errors or inconsistencies.

Assessment of risk of bias in included studies-Two review authors assessed the methodological quality of the selected trials according to the methods set out in Chapter 8 of the Cochrane Handbook for Systematic Reviews of Interventions (Higgins 2009). We considered the following domains:

1. sequence generation;

2. allocation concealment (selection bias);

3. blinding (masking) of participants, personnel and outcome assessors;

4. incomplete outcome data (attrition bias);

5. selective outcome reporting; and

6. other sources of bias.

We documented relevant information on each domain in a 'Risk of Bias' table for each study. Each assessor assigned a judgment relating to whether the study was adequate with regard to the risk of bias for each domain's entry. A judgment of 'Yes' indicated low risk of bias, 'No' indicated high risk of bias, and 'Unclear' indicated unclear or unknown risk of bias. We contacted the authors of trials for additional information on domains judged to be 'Unclear'. If the authors did not respond within four weeks, we assigned a judgment on the domain based on the available information. We documented agreement between review authors and resolved discrepancies by consensus.

Measures of treatment effect-We reported dichotomous variables as risk ratios (RRs) with $95 \%$ confidence intervals (CIs). We reported continuous variables as mean and standard deviation if data were normally distributed, or as median and inter-quartile range if data were not normally distributed. We used standardized mean differences in instances where various measurement tools were used to assess the same outcome. 
Unit of analysis issues-The unit of analysis was the eye for data on visual acuity, ME measurements and ocular complications. The unit of analysis was the individual for demographic characteristics, economic, quality of life and visual functioning.

Dealing with missing data-We attempted to contact authors for missing data. If the authors did not respond within four weeks, we imputed data where possible using available information such as $\mathrm{P}$ values or confidence intervals (CIs).

\section{Protocol for future review}

Assessment of heterogeneity-We did not assess heterogeneity since pooled estimates of the treatment effect were not included in this review. If additional studies are considered during a future update of this review, we will assess heterogeneity by examining study characteristics and forest plots of the results. We will use the $\mathrm{I}^{2}$ statistic to assess the impact of statistical heterogeneity, interpreting an $\mathrm{I}^{2}$ value of $50 \%$ or more as significant.

Assessment of reporting biases-Since pooled estimates of treatment effect across studies were not included, we did not examine funnel plots to assess reporting biases. If considered during a future update of this review, we will examine funnel plots from each meta-analysis to assess reporting bias.

Data synthesis-We will use the following guidelines for future updates of this review. When three or more trials are available, the data will be analyzed using a random-effects model. If significant heterogeneity is found, we will report results in tabular form.

Dichotomous outcome variables will include the proportion of patients with at least a 15 letter gain or loss in visual acuity, the proportion experiencing each complication or adverse event, and the proportion requiring additional treatments, at six months and other follow-up times. Categorical outcome variables will include follow-up period. Continuous outcome variables will include mean changes in visual acuity and central macular thickness over time. We will analyze measurements comparing dose and frequency effects separately.

Subgroup analysis and investigation of heterogeneity-If data are available during a future update of this review we will stratify by anti-VEGF agent, clinical subtype (ischemic and non-ischemic), duration since onset and baseline BCVA, and perform subgroup analyses to identify possible sources of heterogeneity.

Sensitivity analysis-We did not perform sensitivity analyses. We will consider sensitivity analyses for future updates of this review to examine how strongly related our review results are to decisions and assumptions that have been made during the review. We will investigate the impact of quasi-randomized studies, studies with lower methodological quality (e.g. domains judged to be inadequate with regard to risk of bias, marked 'No' or 'Unclear' in the 'Risk of bias' table), unpublished data and industry-funded studies. 


\section{RESULTS \\ Description of studies}

See: Characteristics of included studies; Characteristics of excluded studies; Characteristics of ongoing studies.

Results of the search-The electronic search on 10 August 2010 yielded a total of 123 non-duplicate titles with accompanying abstracts. We screened full-text articles corresponding to 34 possibly relevant titles, and two definitely relevant titles, which identified two RCTs comparing an anti-VEGF treatment to sham injection. There were no RCTs comparing anti-VEGF agents to no treatment.

Included studies-We found two trials that met our inclusion criteria (CRUISE 2010; Wroblewski 2009). Wroblewski 2009 was a Phase II, double-masked, randomized, shamcontrolled trial of pegaptanib sodium for non-ischemic CRVO-ME of not more than six months duration. In this trial 98 participants received either $0.3 \mathrm{mg}(\mathrm{n}=33)$ or $1.0 \mathrm{mg}(\mathrm{n}=$ 33) pegaptanib sodium or sham injection $(n=32)$, with treatment administered every six weeks (five times in total) for 30 weeks. CRUISE 2010 was a Phase III, double-masked, randomized, sham-controlled trial of ranibizumab for predominantly non-ischemic CRVOME of mostly less than 12 months duration. In this trial 392 participants received either 0.3 $\mathrm{mg}(\mathrm{n}=132)$ or $0.5 \mathrm{mg}(\mathrm{n}=130)$ ranibizumab (Lucentis) or sham injection $(\mathrm{n}=130)$, with treatment administered every month (six times in total) for six months. The table 'Characteristics of included studies' details a full summary of each of these trials.

The two trials included patients with broadly similar baseline characteristics. The mean age and percentage of male participants was similar in the two trials, at 68 years with 57\% male participants in the CRUISE trial and 63 years with 53\% male participants in the pegaptanib sodium trial. The mean time between occlusive event and study entry was approximately 80 days in the pegaptanib sodium trial, whilst the median time from diagnosis, which may be later than the occlusive event, to screening in the CRUISE trial was two months with a range of less than one month to 27 months. The mean BCVA at baseline was approximately 48 letters (Snellen 20/100) in both trials. The percentage of patients with a poor presenting BCVA of less than 35 letters was very similar, ranging from $20 \%$ to $25 \%$ in the CRUISE trial and $19 \%$ to $24 \%$ in the pegaptanib sodium trial. The mean baseline CRT was similar in the two studies, ranging between $632 \mu \mathrm{m}$ and $688 \mu \mathrm{m}$.

Excluded studies-We excluded one trial because it compared treatment with bevacizumab to combined treatment with bevacizumab and timolol-dorzolamide, with no sham injection or observation group. Furthermore, this trial combined patients with both BRVO and CRVO, and the sample size was insufficient for analysis of CRVO-ME specifically (Byeon 2009) (See the 'Characteristics of excluded studies' table for further details). Whilst we did not conduct a separate electronic search for study designs less rigorous than the randomized or quasi-randomized controlled trial, numerous interventional case series and case reports were identified, in which anti-VEGF agents were used for the treatment of CRVO-ME, and these are summarized in Table 1 'Interventional case series' 
and Table 2 'Case Reports', respectively. However, these did not meet the inclusion criteria for the systematic review. Table 3 shows the 'Details of other excluded non-RCTs'.

\section{Risk of bias in included studies}

The included studies had a low risk of bias in each domain (See Figure 1). In both studies one eye was enrolled in the study per participant. In CRUISE 2010 the authors specified that where both eyes met the inclusion criteria, the eye with the worse BCVA at screening was selected.

Allocation-Both studies used stratified randomization to obtain balanced treatment assignments according to study center and baseline best corrected visual acuity. Both studies used a dynamic randomization method to check that at the end of the randomization process the treatment assignment groups were balanced on the stratification factors of interest. Both studies were therefore considered to have a low risk of bias in the sequence generation domain. CRUISE 2010 did not describe in detail the method of concealment of the allocations, and so in this domain the risk of bias was considered 'unclear'. In Wroblewski 2009 the authors specified that medication kits were identified by randomization number, that all kits were similar in appearance, and that the allocation was conveyed to the injecting ophthalmologist by the study co-ordinator in a way that did not inform the treating ophthalmologist or participant of the allocation.

Blinding-Both studies were considered to have a low risk of bias in this domain. In both studies, the participants, examining ophthalmologists and other clinical examiners were masked to the treatment allocation. The ophthalmologists performing the intravitreal injections, who performed either a sham injection or a drug injection, were not involved in reviewing the participants at their follow-up assessments. In both studies patients who were randomized to the sham group were treated similarly to those in the treatment groups, except that the hub of a syringe was placed against the injection site and the plunger depressed to mimic an injection, without globe penetration.

Incomplete outcome data-In CRUISE 2010, the percentage of patients who dropped out of follow up before six months differed between groups. Specifically, $2.3 \%$ in the 0.3 $\mathrm{mg}$ ranibizumab group, $8.5 \%$ in the $0.5 \mathrm{mg}$ ranibizumab group and $11.5 \%$ in the sham group did not complete six-month follow up. Similarly, the percentage of patients who discontinued treatment before receiving six consecutive injections differed between groups, at $3.0 \%$ in the $0.3 \mathrm{mg}$ group, $7.7 \%$ in the $0.5 \mathrm{mg}$ group and $12.3 \%$ in the sham group. The main reason given for all incomplete outcome data was patient or physician choice, but further detail was not specified. In the smaller pegaptanib sodium trial (Wroblewski 2009) a total of six participants $(6 \%)$ withdrew. Specifically, three participants withdrew from the $0.3 \mathrm{mg}$ group, one from the $1 \mathrm{mg}$ group and two from the sham group. In addition, one participant in the sham group discontinued through non-compliance. All five consecutive injections were received by $81 \%$ of participants in the $0.3 \mathrm{mg}$ group, $90 \%$ of participants in the $1 \mathrm{mg}$ group and $88 \%$ of participants in the sham group. In both studies, the authors imputed missing values for efficacy outcomes using the last-observation-carried-forward method and efficacy analyses were conducted on the intention-to-treat population of 
randomized participants. However, the imbalance in incomplete outcome data in these relatively small trials may have introduced bias into the reported outcomes, and therefore the risk of bias in both trials was considered 'unclear.'

Selective reporting-CRUISE 2010 reported all pre-specified primary and secondary outcomes listed in the study protocol on ClinicalTrials.gov (NCT00485836). The protocol for Wroblewski 2009 (NCT00088283) did not include prespecified outcome measures. Whilst all outcomes that would be expected were included, and both positive and negative results were reported without apparent bias, we were not able to exclude the possibility of selective reporting and considered the study 'unclear' in this domain.

Other potential sources of bias-We did not identify any other potential threats to validity in Wroblewski 2009. In CRUISE 2010, three patients (2\%) included in the $0.5 \mathrm{mg}$ ranibizumab group had more than ten disc areas of capillary non-perfusion, specifically 112 , 113 and 109 disc areas, compared to no patients in either the sham or $0.3 \mathrm{mg}$ groups. Furthermore, three participants in the $0.5 \mathrm{mg}$ group (2\%), compared to one in the sham group and none in the $0.3 \mathrm{mg}$ group, were included whose time from diagnosis to screening exceeded the specified inclusion criteria of up to 12 months, with a longest duration of 27 months for a participant in the $0.5 \mathrm{mg}$ group. These differences in baseline characteristics between the groups were small, but we were not able to exclude the possibility of associated bias in the outcomes for the $0.5 \mathrm{mg}$ group and therefore judged the study to have an 'unclear' risk of bias.

\section{Effects of interventions}

In Wroblewski 2009, in which pegaptanib sodium $0.3 \mathrm{mg}$ or $1.0 \mathrm{mg}$ given five times at sixweek intervals over a 30-week period was compared to sham injections, there was no significant difference between groups in the primary endpoint. Specifically, in the sham group nine patients (28\%) gained 15 or more letters at week 30, compared to 12 patients $(36 \%)$ in the $0.3 \mathrm{mg}$ pegaptanib sodium treatment group $(\mathrm{P}=0.48)$, and 13 patients $(39 \%)$ in the $1.0 \mathrm{mg}$ pegaptanib sodium treatment group $(\mathrm{P}=0.35)$. However, there was a significant difference in average visual acuity gain at week 30 in the $1.0 \mathrm{mg}$ treatment group, who gained an average of 9.9 letters from baseline, compared to the sham group who lost an average 3.2 letters ( $\mathrm{P}=0.02,95 \% \mathrm{CI} 1.5$ to 24.6 letters). Those treated with $0.3 \mathrm{mg}$ pegaptanib sodium also gained an average 7.1 letters from baseline, but the change was not significantly different to that of the sham group ( $\mathrm{P}=0.09,95 \% \mathrm{CI}-1.3$ to 21.8 letters). However, there was a significant difference between both treatment groups and the sham group in the risk of losing 15 or more letters at week 30 compared to baseline. Specifically, $9 \%$ in the $0.3 \mathrm{mg}$ group ( $\mathrm{P}=0.03$, RR $0.29 ; 95 \% \mathrm{CI}, 0.09$ to 0.96$)$ and $6 \%(\mathrm{P}=0.01, \mathrm{RR}$ $0.19 ; 95 \% \mathrm{CI}, 0.05$ to 0.82 ) in the $1.0 \mathrm{mg}$ group lost 15 letters, compared to $31 \%$ in the sham group. There was a near-linear mean reduction in central retinal thickness from baseline over time in the sham group. In contrast, there was a significant mean reduction from baseline to week three in the $0.3 \mathrm{mg}$ group (of $329 \mu \mathrm{m}$ ) and $1.0 \mathrm{mg}$ group (of $198 \mu \mathrm{m}$ ), compared to the sham group (of $40 \mu \mathrm{m}, \mathrm{P}=0.001$ ). This mean reduction subsequently rebounded slightly, but the mean reduction remained greater at all time points in the treatment groups than in the sham group. Iris or retinal neovascularization developed before 
30 weeks in three patients in the sham group, and one patient in each of the treatment groups. No serious or adverse events were reported. No economic, quality of life or visual functioning data were included. In CRUISE 2010, in which ranibizumab (Lucentis®) $0.3 \mathrm{mg}$ or $0.5 \mathrm{mg}(\mathrm{n}=130)$ was given at monthly intervals for six months and was compared to sham injections $(n=130)$, there was a significant difference in the mean change from baseline BCVA at six months in both treatment groups compared to sham $(\mathrm{P}<0.0001)$. Specifically, the $0.3 \mathrm{mg}$ group gained a mean 12.7 letters (95\% CI 9.9 to 15.4 ) and the 0.5 mg group gained a mean 14.9 letters (95\% CI 12.6 to 17.2), compared with 0.8 letters in the sham group (95\% CI -2.0 to 3.6). This improvement occurred rapidly in patients receiving ranibizumab, who gained an average 9 letters one week after the first injection. At six months the percentage of patients gaining 15 letters or more from baseline was significantly higher in both treatment groups compared to sham $(\mathrm{P}<0.0001$ for each pair-wise comparison to sham). Specifically, $46.2 \%$ of the $0.3 \mathrm{mg}$ group, $47.7 \%$ of the $0.5 \mathrm{mg}$ group, versus $16.9 \%$ of the sham group gained 15 letters. The differences between the treatment groups and the sham group were significant at seven days and all monthly time points to six months ( $\mathrm{P}<0.0001$ for each pair-wise comparison to sham). The percentage of patients in the treatment groups losing 15 or more letters at six months was also significantly less than in the sham group ( $\mathrm{P}<0.005$ for each pairwise comparison to sham). Specifically, $3.8 \%$ of the $0.3 \mathrm{mg}$ group and $1.5 \%$ of the $0.5 \mathrm{mg}$ group lost 15 or more letters, compared to $15.4 \%$ of the sham group. The mean difference in central foveal thickness (CFT) from baseline was significantly greater in both treatment groups compared to sham at all time points from seven days to six months $(\mathrm{P}<0.0001$ for each ranibizumab group versus sham at each time point). Specifically, the mean reduction was $-433.7 \mu \mathrm{m}$ (95\% CI -484.9 to -382.6$)$ in the 0.3 $\mathrm{mg}$ group, $-452.3 \mu \mathrm{m}$ (95\% CI -497.0 to -407.6 ) in the $0.5 \mathrm{mg}$ group, and only $-167.7 \mu \mathrm{m}$ (95\% CI -221.5 to -114.0) in the sham group. There were few serious adverse ocular events at six months; one patient in the sham group developed a vitreous hemorrhage and one patient in the $0.5 \mathrm{mg}$ group developed iris neovascularization. Two patients in each of the ranibizumab groups developed cataract. Some systemic serious adverse events occurred in all groups by six months; one non-fatal myocardial infarct affected a patient in each group. In addition, one patient in the $0.5 \mathrm{mg}$ group had a transient ischemic attack and angina pectoris; and one patient in the $0.3 \mathrm{mg}$ group had a retinal artery occlusion. The treatment groups had a significantly greater mean change from baseline in the National Eye Institute Visual Functioning Questionnaire 25 item instrument (NEI VFQ-25) score at six months. Specifically, the score increased by 7.1 (95\% CI 5.2 to 9.0 ) in the $0.3 \mathrm{mg}$ group, 6.2 (95\% CI 4.3 to 8.0 ) in the $0.5 \mathrm{mg}$ group, and 2.8 (95\% CI 0.8 to 4.7$)$ in the sham group $(\mathrm{P}<0.05$ for each ranibizumab group versus sham). No economic data were included.

Analysis 1.1 graphically illustrates the chance, or relative risk (RR), of having an improvement of 15 or more letters on the ETDRS visual acuity chart at 26 to 30 weeks of follow-up, for each dose of each anti-VEGF agent as compared to receiving a sham injection. Specifically, treatment with $0.3 \mathrm{mg}$ or $0.5 \mathrm{mg}$ ranibizumab, rather than sham, was associated with atleast a $2 \frac{1}{2}$ times increase in the probability of achieving the primary outcome. For the $0.3 \mathrm{mg}$ group the RR was 2.73 (95\% CI 1.79 to 4.17; fixed-effect model), and for the $0.5 \mathrm{mg}$ group the RR was 2.82 (95\% CI 1.85 to 4.29 ; fixed-effect model). In contrast, there was a non-significant increase in the chance of achieving the primary 
outcome comparing $0.3 \mathrm{mg}$ or $1.0 \mathrm{mg}$ treatment with pegaptanib sodium to sham injection. Specifically, the RR for the $0.3 \mathrm{mg}$ group was 1.29 (95\% CI 0.63 to 2.64; fixed-effect model), and the RR for the $1.0 \mathrm{mg}$ group was 1.40 (95\% CI 0.70 to 2.81 ).

Aside from these RCTs, the remainder of the literature identified through this review's electronic search was based on open-label, prospective studies, retrospective chart reviews, case reports and case series with relatively short follow-up periods. A summary of these studies is provided in Table 1 and Table 2 .

\section{DISCUSSION}

\section{Summary of main results}

Allowing for variability resulting from the relatively small sample sizes, these two RCTs included participants with broadly similar baseline characteristics. The outcomes in the sham groups were also broadly similar, although sham participants in the trial of pegaptanib sodium (Wroblewski 2009) more closely followed the pattern reported previously (CVOS Group 1995). More specifically, after six months the sham group in the CRUISE trial (CRUISE 2010) experienced a negligible mean improvement in BCVA, and a similar proportion of patients either gained or lost 15 or more letters on the ETDRS chart $(\sim 16 \%)$. There was some reduction in ME from baseline, with an average central foveal thickness (CFT) change of $167.7 \mu \mathrm{m}$. Participants reported minimal functional gain, with a 2.8-point change in score from baseline on the NEI VFQ-25 instrument. Similarly, the sham group in the pegaptanib sodium trial (Wroblewski 2009) had a small mean deterioration in BCVA at 30 weeks, with approximately $30 \%$ of participants either gaining or losing 15 or more letters on the ETDRS chart. A similar reduction in ME thickness over time $(148 \mu \mathrm{m})$ was observed to that in the sham group of the CRUISE trial. In both trials, repeated treatment with the antiVEGF agent was associated with improved outcomes at six months (CRUISE 2010) or 30 weeks (Wroblewski 2009), and no safety concerns were identified in this time. The CRUISE trial demonstrated the efficacy of six consecutive injections of either $0.5 \mathrm{mg}$ or 0.3 $\mathrm{mg}$ ranibizumab (Lucentis ${ }^{\circledR}$ ), given at monthly intervals, compared to sham injection, in all primary and secondary endpoints investigated (CRUISE 2010). Participants treated with ranibizumab gained between 13 and 15 letters at six months, with $46 \%$ and $48 \%$ gaining 15 or more letters and only $2 \%$ to $4 \%$ losing 15 or more letters. Significant resolution of ME was demonstrated by a mean reduction from baseline CFT of between $434 \mu \mathrm{m}$ and $452 \mu \mathrm{m}$. A significant participant-reported functional gain was also supported by an increase from baseline in the NEI VFQ-25 score of between 6 and 7 points. For all outcomes except the latter, the higher dose of $0.5 \mathrm{mg}$ ranibizumab appeared to have a slightly greater effect than the $0.3 \mathrm{mg}$ dose, but the trial was not designed to test for a significant difference between doses. In the smaller Phase II trial of five consecutive injections of either $1.0 \mathrm{mg}$ or $0.3 \mathrm{mg}$ pegaptanib sodium (Macugen $\left.{ }^{\circledR}\right)$, given at six-week intervals and compared to sham injection, efficacy was demonstrated for some but not all outcomes (Wroblewski 2009). Participants treated with pegaptanib sodium gained a more modest 7 to 10 letters, and the latter gain in the $1.0 \mathrm{mg}$ group was significant. Compared to sham injection, treated participants also had a slightly greater, though non-significant, reduction in CRT and proportion gaining 15 or more letters on the ETDRS chart. Furthermore, a significantly 
smaller proportion of treated participants, between $6 \%$ and $9 \%$ lost 15 or more letters compared to the sham group. Thus, both anti-VEGF agents were demonstrated to enhance the anatomical resolution of ME, to stabilize the visual acuity in some participants and to improve the visual acuity in others, as compared to sham injection.

\section{Overall completeness and applicability of evidence}

One main limitation of both trials was their relatively small sample size (CRUISE 2010; Wroblewski 2009). This was especially relevant in the pegaptanib sodium trial, which lacked sufficient power to identify differences between the treatment and sham groups in the main outcomes of interest (Wroblewski 2009). Neither trial had sufficient power to investigate outcome differences between the two different treatment doses. A second limitation of both trials was the relatively short follow-up periods, of six months and 30 weeks, which did not permit assessment of how long the apparent benefits of treatment with ranibizumab and pegaptanib sodium are sustained. Ocular or systemic adverse events occurring at a longer latency from treatment may also have been missed. Twelve-month follow-up data for the CRUISE trial are anticipated in the near future, and will be valuable in this regard.

Whilst the treatment of CRVO-ME with ranibizumab or pegaptanib sodium appears promising, the applicability of the available trial data to clinical practice is still relatively limited, and there were no RCT data on bevacizumab or other antiVEGF agents. The inclusion and exclusion criteria of the two trials were such that the outcome data can not be extrapolated to important sub-groups of patients in clinical practice. For example, approximately $20 \%$ of acute presentations of CRVO are ischemic (Hayreh 1983; Hayreh 1994), and up to a third of patients convert from the non-ischemic to the ischemic subtype, most frequently in the first four months (CVOS Group 1997), but participants with ischemic CRVO were excluded in these trials. Secondly, a substantial proportion of patients in clinical practice have had persisting CRVO-ME for more than one year, but such participants were mostly excluded. Thirdly, patients with previous retinal vein occlusion, or other co-morbid eye disease including diabetic retinopathy and age-related macular degeneration were also necessarily excluded, but age and diabetes are among the established risk factors for CRVO (Shahsuvaryan 2003) and it is not uncommon for patients to have multiple ocular and systemic pathologies. Fourthly, the CVOS Study reported that $29 \%$ of patients with CRVO present with a visual acuity of 20/40 or better (CVOS Group 1997), but as these participants were mostly excluded it is not possible to determine whether treatment confers sufficient benefit in this group to outweigh the risks associated with intravitreal injection.

Many important questions on the management of CRVO-ME remain unanswered. For example, does the timing of treatment initiation matter? How long is any treatment benefit sustained and what is the optimal re-treatment frequency for each anti-VEGF agent? How many treatments are required to achieve a stable outcome? What proportion of patients develop ME which is refractory to further treatment, and at what latency from previous treatment cessation? Is the apparently low incidence of ocular and systemic adverse events 
maintained in the longer term? Further RCT data is anticipated in the near future which will begin to address these questions.

\section{Quality of the evidence}

The two included RCTs were relatively small but were well designed with a low risk of bias in the majority of domains. They can therefore be considered to provide reasonably good evidence on short-term outcomes for the specific cohort of participants studied.

Data from numerous non-randomized studies was also reviewed (see Additional Table 1 and Table 2), although a comprehensive search for such data was not performed. Comparison of the results of these studies was challenging for a number of reasons. Firstly, the studies reported variable baseline investigations, follow up and outcome measures. Secondly, some studies included only patients with non-ischemic CRVO-ME at baseline, others only ischemic CRVO-ME, and many others a mixed or unspecified cohort of patients. Since the natural history and visual prognosis in CRVO has been found to be very variable (CVOS Group 1997), summating outcomes for mixed patient cohorts, especially with small sample sizes, is likely to be misleading, with either over or underestimation of possible treatment effects. Thirdly, different anti-VEGF agents, at different doses, were administered intravitreally at variable times from the onset of symptoms or from diagnosis of CRVO-ME. Fourthly, some studies included treatment with a single injection, others multiple injections given at variable intervals during follow up, and some studies included patients treated previously with intravitreal corticosteroid. Also, the numbers of patients included in these studies were relatively small and the follow-up periods relatively short (12 months). Without baseline randomization or a control or observation group to provide a valid comparison with the treatment arm, it was difficult to draw any conclusions about the effectiveness or safety of the treatments.

\section{Agreements and disagreements with other studies or reviews}

We are not aware of any other systematic reviews on the use of anti-VEGF agents for the treatment of CRVO-ME. However, these agents have been administered intravitreally in numerous other ophthalmological contexts, with similar safety findings. Studies investigating the efficacy and safety of repeat injections every four to six weeks for wet agerelated macular degeneration, proliferative diabetic retinopathy, diabetic ME, pathological myopia and neovascular glaucoma have reported no serious adverse events (Lynch 2007). However, the total number of treated patients remains too small, and the follow-up periods too short to detect serious adverse events that may occur at low incidence, or at long latency from the treatment period. A review of reported side effects has included lid irritation, ocular discomfort and foreign body sensation, transient vision blurring, subconjunctival hemorrhage, mild anterior chamber inflammation and mild vitritis, uveitis and raised IOP (Lynch 2007). Posterior vitreous detachment, retinal tears, retinal detachment and endophthalmitis have also been reported in a few cases (Lynch 2007; Wu 2008). Systemic adverse events including stroke, myocardial infarction and blood pressure elevation have been reported following intravenous administration at doses more than 300 times higher than are used for ophthalmic indications (Lynch 2007). Wu et al. reported that systemic adverse events have also occurred by one year of follow up in $1.5 \%$ of patients following 
intravitreal administration of 4303 bevacizumab injections into 1310 eyes. These adverse events included acute systolic blood pressure elevation $(0.59 \%)$, cerebrovascular accident $(0.5 \%)$, myocardial infarction $(0.4 \%)$, iliac artery aneurysm $(0.17 \%)$, toe amputation $(0.17 \%)$ and death $(0.4 \%)$ (Wu 2008).

It will be important to determine the relative effectiveness and safety of anti-VEGF agents versus other interventions for the treatment of CRVO-ME, but no head-to-head trial data are available yet. Comparison with RCT data on intravitreal corticosteroids will be particularly interesting, but is of limited value at present. For example, the SCORE trial of $1 \mathrm{mg}$ or $4 \mathrm{mg}$ intravitreal triamcinolone injection at four-month intervals versus observation (SCORE 2009) and the Ozurdex trial of a single $0.35 \mathrm{mg}$ or $0.7 \mathrm{mg}$ dexamethasone implant versus sham procedure (Haller 2010) used different primary outcome measures and different periods of follow up. Furthermore, differences in the outcomes of the sham and observation groups in these trials suggest that participants recruited to each trial were, on average, different to those recruited to the anti-VEGF trials. For example, in the observation group of the SCORE trial, fewer participants (7\%) gained 15 letters or more at 12 months, compared to the sham groups of the Ozurdex trial at 180 days (12\%), the CRUISE trial at six months $(17 \%)$ and the trial by Wroblewski et al. at 30 weeks $(28 \%)$.

\section{AUTHORS' CONCLUSIONS}

\section{Implications for practice}

In summary, the available RCT evidence suggests that repeated treatment of non-ischemic CRVO-ME with the anti-VEGF agents ranibizumab or pegaptanib sodium may improve numerous outcomes at six months. However, their effectiveness and safety over longer periods of follow up has yet to be determined, and there are no RCT data on their use in the treatment of ischemic CRVO-ME. The optimal timing of initial treatment with different anti-VEGF agents and subsequent re-treatment has not yet been determined. Furthermore, the impact of prior or combined treatment with intravitreal corticosteroid, or other treatments, also needs to be explored, and different subgroups of patients may have different outcomes. For example, patients with differing degrees of ischemias at the onset of CRVO$\mathrm{ME}$, and with differing durations of CRVO-ME may represent important subgroups. However, the identification of such subgroups is limited by a lack of population-based data on the risk factors for, and prevalence of, CRVO-ME, and a paucity of data on the natural history and visual prognosis of untreated CRVO-ME. The outcomes of the numerous RCTs that are currently in progress (see table on the 'Characteristics of ongoing studies') will address some of these questions. It is therefore too early to recommend the use of antiVEGF agents for the treatment of CRVO-ME in clinical practice. It is also not yet possible to determine the potential economic impact of the use of anti-VEGF agents in this clinical context, but this will be reassessed if data become available.

\section{Implications for research}

Many important questions remain unanswered by the existing studies. Future research should focus on double-masked RCTs that compare different anti-VEGF agents, at different doses and treatment intervals, to sham injection. RCTs comparing different anti-VEGF 
agents to observation alone would also give valuable insight into the untreated history of CRVO-ME without any placebo effect. It will be important for studies to define subgroups of patients with ischemic versus non-ischemic CRVO-ME, or to specify the degree of ischemias at baseline and during follow-up. Studies that include patients with CRVO-ME and BRVO-ME within the same treatment arm will need to stratify by the type of RVO at the time of randomization and when analyzing outcomes. It will also be important to consider separately patients who have received prior treatment with other agents (e.g. intravitreal triamcinolone). A further variable to consider in any analysis will be time since onset of symptoms. Further epidemiological data from different populations on the risk factors for developing ME in CRVO are also needed. The answers to such questions would valuably inform future economic analyses.

\section{Acknowledgments}

We are especially grateful to Kristina Lindsley, Anupa Shah and Ann Ervin for their guidance and comments on this review and to Iris Gordon for performing the electronic searches. We wish to thank Michele Melia, Quan Dong Nguyen and Mariacristina Parravano for their comments on the protocol of this review. We would also like to thank Richard Wormald, Barbara Hawkins and all the peer reviewers who made valuable comments on the review manuscript.

\section{SOURCES OF SUPPORT}

Internal sources

- The UK-US Fulbright Commission, UK.

Tasanee Braithwaite received financial support from the UK-US Fulbright Commission

External sources

- Contract N-01-EY-2-1003 and Grant 1 U01 EY020522-01, National Eye Institute, National Institutes of Health, USA.

\section{APPENDICES}

\section{Appendix 1. CENTRAL search strategy}

\#1 MeSH descriptor Macular Edema, Cystoid

\#2 MeSH descriptor Edema

\#3 MeSH descriptor Macula Lutea

\#4 macula* near/3 oedema

\#5 macula* near/3 edema

\#6 CME or CMO

\#7 (\#1 OR \#2 OR \#3 OR \#4 OR \#5 OR \#6)

\#8 MeSH descriptor Retinal Vein Occlusion

\#9 MeSH descriptor Retinal Vein

\#10 retina* near/3 (vein* or occlu* or obstruct* or clos* or stricture* or steno* or block* or embolism*) 


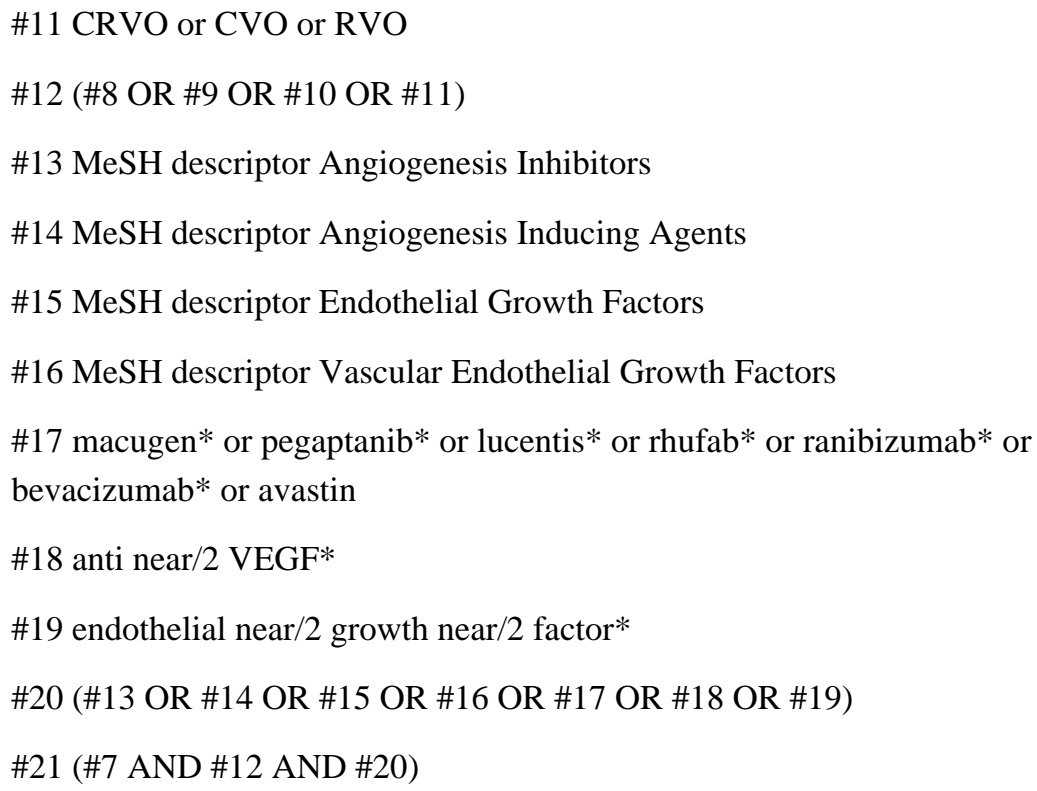

\section{Appendix 2. MEDLINE search strategy}

1. randomized controlled trial.pt.

2. (randomized or randomised).ab,ti.

3. placebo.ab,ti.

4. dt.fs.

5. randomly.ab,ti.

6. trial.ab,ti.

7. groups.ab,ti.

8. or $/ 1-7$

9. $\exp$ animals/

10. exp humans/

11. 9 not (9 and 10)

12. 8 not 11

13. exp macular edema cystoid/

14. exp edema/

15. exp macula lutea/

16. (macula $\$$ adj3 oedema).tw.

17. (macula $\$$ adj3 edema).tw.

18. (CME or CMO).tw. 
19. or/13-18

20. exp retinal vein occlusion/

21. exp retinal vein/

22. ( (vein $\$$ or occlu $\$$ or obstruct $\$$ or clos $\$$ or stricture $\$$ or steno $\$$ or block $\$$ or embolism\$) adj3 retina\$).tw.

23. (CRVO or CVO or RVO).tw.

24. or $/ 20-23$

25. exp angiogenesis inhibitors/

26. exp angiogenesis inducing agents/

27. exp endothelial growth factors/

28. exp vascular endothelial growth factors/

29. (macugen $\$$ or pegaptanib\$ or lucentis $\$$ or rhufab\$ or ranibizumab\$ or bevacizumab $\$$ or avastin).tw.

30. (anti adj2 VEGF\$).tw.

31. (endothelial adj2 growth adj2 factor\$).tw.

32. or $/ 25-31$

33. 19 and 24 and 32

The search filter for trials at the beginning of the MEDLINE strategy is from the published paper by Glanville (Glanville 2006)

\section{Appendix 3. EMBASE search strategy}

1. exp randomized controlled trial/

2. exp randomization/

3. exp double blind procedure/

4. exp single blind procedure/

5. random $\$ . t w$.

6. or/1-5

7. (animal or animal experiment).sh.

8. human.sh.

9. 7 and 8

10. 7 not 9

11. 6 not 10

12. exp clinical trial/ 
13. (clin $\$ \operatorname{adj} 3$ trial\$).tw.

14. ((singl\$ or doubl\$ or trebl\$ or tripl\$) adj3 (blind $\$$ or mask $\$)$ ).tw.

15. exp placebo/

16. placebo\$.tw.

17. random $\$ . t w$.

18. exp experimental design/

19. exp crossover procedure/

20. exp control group/

21. exp latin square design/

22. or $/ 12-21$

23. 22 not 10

24. 23 not 11

25. exp comparative study/

26. exp evaluation/

27. exp prospective study/

28. (control\$ or propspectiv\$ or volunteer\$).tw.

29. or $/ 25-28$

30. 29 not 10

31. 30 not (11 or 23$)$

32. 11 or 24 or 31

33. exp retina macula cystoid edema/

34. exp eye edema/

35. exp retina macula lutea/

36. (macula $\$$ adj3 oedema).tw.

37. (macula $\$$ adj3 edema).tw.

38. (CME or CMO).tw.

39. or $/ 33-38$

40. exp retinal vein occlusion/

41. exp retina vein/

42. ((vein $\$$ or occlu $\$$ or obstruct $\$$ or clos $\$$ or stricture $\$$ or steno $\$$ or block $\$$ or embolism\$) adj3 retina\$).tw.

43. (CRVO or CVO or RVO).tw. 

44. or $/ 40-43$
45. exp angiogenesis/
46. exp angiogenesis inhibitors/
47. exp angiogenic factor/
48. exp endothelial cell growth factor/
49. exp vasculotropin/
50. (macugen $\$$ or pegaptanib\$ or lucentis $\$$ or rhufab $\$$ or ranibizumab $\$$ or bevacizumab \$ or avastin).tw.
51. (anti adj2 VEGF\$).tw.
52. (endothelial adj2 growth adj2 factor\$).tw.
53. or $/ 45-52$
54. 39 and 44 and 53
55. 32 and 54

\section{Appendix 4. LILACS search strategy}

macula\$ oedema or macula\$ edema or CME or CMO

AND vein\$ or occlu\$ or obstruct\$ or CRVO or CVO or RVO

AND angiogenesis or endothelial growth factor or macugen\$ or pegaptanib\$ or lucentis \$ or rhufab\$ or ranibizumab\$ or bevacizumab\$ or avastin

\section{Appendix 5. CINAHL search strategy}

macula\$ oedema or macula\$ edema or CME or CMO

AND vein\$ or occlu\$ or obstruct\$ or CRVO or CVO or RVO

AND angiogenesis or endothelial growth factor or macugen\$ or pegaptanib\$ or lucentis or rhufab\$ or ranibizumab\$ or bevacizumab\$ or avastin

\section{Appendix 6. OpenSIGLE search strategy}

macula* oedema or macula* edema or CME or CMO

AND vein* or occlu* or obstruct* or CRVO or CVO or RVO

AND angiogenesis or endothelial growth factor or macugen* or pegaptanib* or lucentis or rhufab* or ranibizumab* or bevacizumab* or avastin

\section{Appendix 7. metaRegister of Controlled Trials search strategy}

(angiogenesis or endothelial growth factor) AND macula oedema 


\section{Appendix 8. ClinicalTrials.gov search strategy}

(Angiogenesis or Endothelial Growth Factor) AND (Macula Oedema)

\section{DATA AND ANALYSES}

\section{Comparison 1. Anti-VEGF versus sham intravitreal injection}

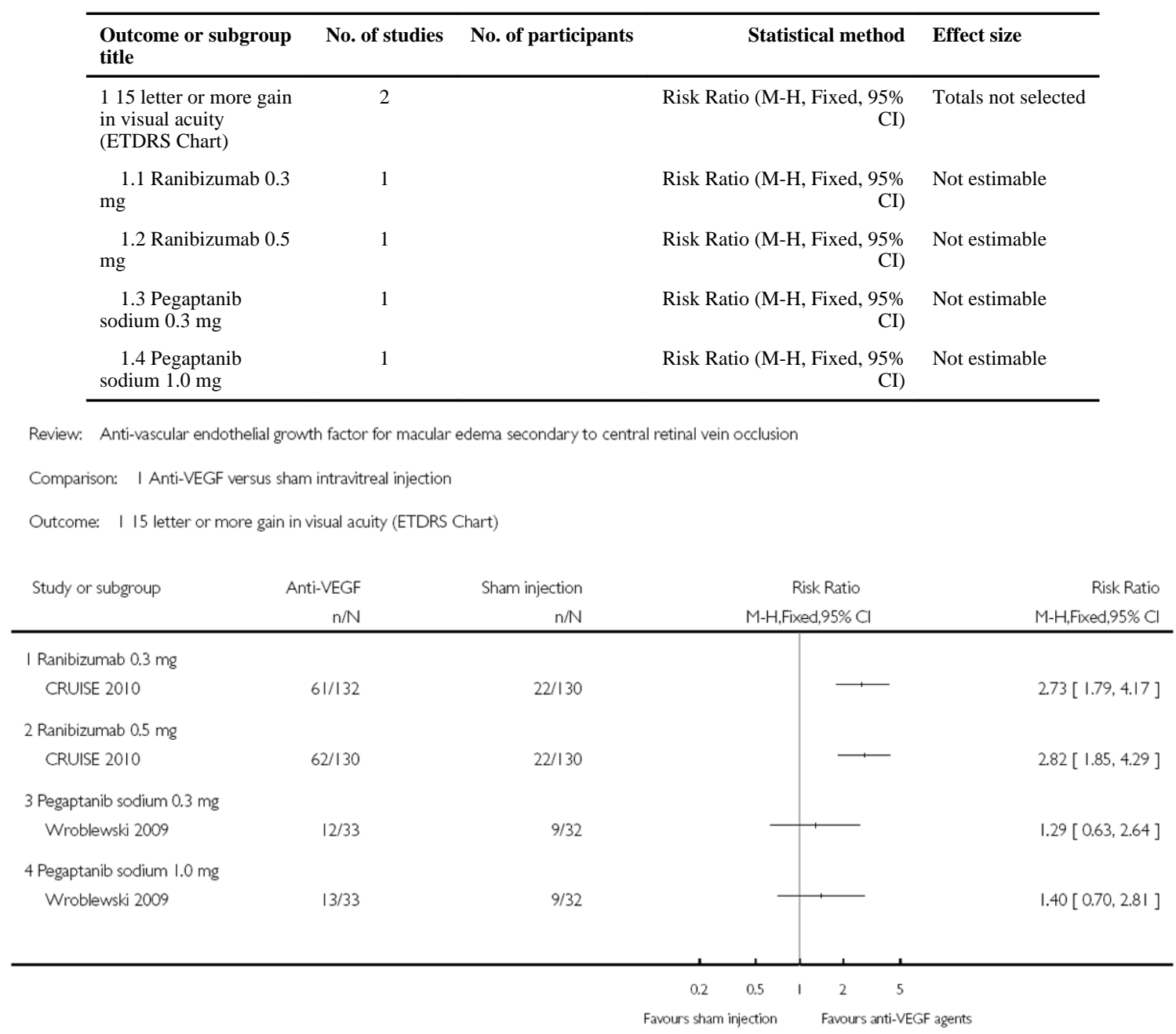

Analysis 1.1.

Comparison 1 Anti-VEGF versus sham intravitreal injection, Outcome 115 letter or more gain in visual acuity (ETDRS Chart).

\section{HISTORY}

Protocol first published: Issue 3, 2008

Review first published: Issue 10, 2010 


\section{DIFFERENCES BETWEEN PROTOCOL AND REVIEW}

We decided to limit the scope of this review to RCTs comparing anti-VEGF agents to placebo or observation

groups. Whilst there are presently no RCTs in which anti-VEGF agents are compared only to other interventions (such as corticosteroids), such head-to-head RCTs will not be included in future updates of this review, in order to maintain the review's focus amidst a rapidly expanding literature.

The primary outcome has been changed from a greater than or equal to 10 letter (ETDRS) improvement in visual acuity, to greater than or equal to 15 letter (ETDRS) improvement in visual acuity, as the latter corresponds to a doubling of the visual angle and is the standard binary outcome measure in clinical trials of treatments in retinal disease (Beck 2007). The follow-up interval is unchanged, at six months.

A secondary binary outcome, of a 15 letter or more (ETDRS) reduction in visual acuity at six months, has been added to more clearly report the proportion of patients experiencing a significant deterioration in visual acuity.

\section{References to studies included in this review}

CRUISE 2010 \{published data only\}. Brown DM, Campochiaro PA, Singh RP, Li Z, Gray S, Saroj N, et al. Ranibizumab for macular edema following central retinal vein occlusion: six-month primary end point results of a phase III study. Ophthalmology. 2010; 117(6):1124-33. [PubMed: 20381871]

Wroblewski 2009 \{published data only\}. Wroblewski JJ, Wells JA 3rd, Adamis AP, Buggage RR, Cunningham ET Jr, Goldbaum M, et al. Pegaptanib sodium for macular edema secondary to central retinal vein occlusion. Archives of Ophthalmology. 2009; 127(4):374-80. [PubMed: 19365011]

\section{References to studies excluded from this review}

Byeon 2009 \{published data only\}. Byeon SH, Kwon OW, Song JH, Kim SE, Park YS. Prolongation of activity of single intravitreal bevacizumab by adjuvant topical aqueous depressant (TimololDorzolamide). Graefe's Archive for Clinical and Experimental Ophthalmology. 2009; 247(1): 35-42.

\section{References to ongoing studies}

Aleris Helse Study \{published data only\}. A randomized study comparing ranibizumab to sham in patients with macular edema secondary to CRVO. Ongoing study March 2007.

BRAVO Study \{published data only\}. Efficacy and Safety of Lucentis for Clinically Significant Macular Edema Secondary to Central Retinal Vein Occlusion (BRAVO). Ongoing study August 2009.

Maturi, RK \{published data only\}. Single site, masked, randomized, controlled study to assess efficacy of Osurdex as adjunct to Avastin compared with Avastin alone in the treatment of patients with macular edema secondary to central or branch retinal vein occlusion. Ongoing study March 2010.

Regeneron Study \{published data only\}. Vascular Endothelial Growth Factor (VEGF) Trap-Eye: Investigation of Efficacy and Safety in Central Retinal Vein Occlusion (Regeneron 2010). Ongoing study July 2009. 
St Erik Eye Study \{published data only . Bevacizumab for Central Retinal Vein Occlusion Study (St. Eriks Eye Hospital 2009). Ongoing study May 2009.

\section{Additional references}

Ach 2007. Ach T, Dawczynski J, Konigsdorffer E, Augsten R, Strobel J. Subjective sensations after intravitreal injection of Bevacizumab [Subjectives empfinden nach intravitrealer Bevacizumabinjektion]. Klinische Monatsblatter fur Augenheilkunde. 2007; 224(3):180-4. [PubMed: 17385118]

Adamis 1996. Adamis AP, Shima DT, Tolentino MJ, Gragoudas ES, Ferrara N, Folkman J, et al. Inhibition of vascular endothelial growth factor prevents retinal ischemia-associated iris neovascularization in a nonhuman primate. Archives of Ophthalmology. 1996; 114(1):66-71. [PubMed: 8540853]

Aiello 1995. Aiello LP, Pierce EA, Foley ED, Takagi H, Chen HRL, Ferrara N, et al. Suppression of retinal neovascularization in vivo by inhibition of vascular endothelial growth factor (VEGF) using soluble VEGFreceptor chimeric proteins. Proceedings of the National Academy of Sciences. 1995; 92(23):10457-61.

Arevalo 2008. Arevalo JF, Garcia RA, Wu L, Rodriguez FJ, Dalma-Weiszhausz J, Quiroz-Mercado H, et al. Radial optic neurotomy for central retinal vein occlusion: results of the Pan-American Collaborative Retina Study Group (PACORES). Retina. 2008; 28(8):1044-52. [PubMed: 18779709]

Bakri 2007a. Bakri SJ, Snyder MR, Reid JM, Pulido JS, Ezzat MK, Singh RJ. Pharmacokinetics of intravitreal ranibizumab (Lucentis). Ophthalmology. 2007; 114(12):2179-82. [PubMed: 18054637]

Bakri 2007b. Bakri SJ, Snyder MR, Reid JM, Pulido JS, Singh RJ. Pharmacokinetics of intravitreal bevacizumab (Avastin). Ophthalmology. 2007; 114(5):855-9. [PubMed: 17467524]

Beck 2007. Beck RW, Maguire MG, Bressler NM, Glassman AR, Lindblad AS, Ferris FL. Visual acuity as an outcome measure in clinical trials of retinal disease. Ophthalmology. 2007; 114(10): 1804-9. [PubMed: 17908590]

Boyd 2002. Boyd SR, Zachary I, Chakravarthy U, Allen GJ, Wisdom GB, Cree IA, et al. Correlation of increased vascular endothelial growth factor with neovascularization and permeability in ischemic central vein occlusion. Archives of Ophthalmology. 2002; 120(12):1644-50. [PubMed: 12470137]

Byeon 2007. Byeon SH, Kwon YA, Oh H, Kim M, Kwon OW. Short-term results of intravitreal Bevacizumab for macular edema with retinal vein obstruction and diabetic macular edema. Journal of Ocular Pharmacology and Therapeutics. 2007; 23(4):387-94. [PubMed: 17803438]

Campochiaro 2008. Campochiaro PA, Hafiz G, Shah SM, Nguyen QD, Ying H, Do DV, et al. Ranibizumab for macular edema due to retinal vein occlusions: implication of VEGF as a critical stimulator. Molecular Therapy. 2008; 16(4):791-9. [PubMed: 18362932]

Campochiaro 2009. Campochiaro PA, Choy DF, Do DV, Gulnar H, Shah SM, Nguyen QD, et al. Monitoring ocular drug therapy by analysis of aqueous samples. Ophthalmology. 2009; 116(11): 2158-64. [PubMed: 19700195]

Catier 2005. Catier A, Tadayoni R, Paques M, Erginay A, Haouchine B, Gaudric A, et al. Characterization of macular edema from various etiologies by optical coherence tomography. American Journal of Ophthalmology. 2005; 140(2):200-6. [PubMed: 15992752]

Costa 2007. Costa RA, Jorge R, Calucci D, Melo LA Jr, Cardillo JA, Scott IU. Intravitreal bevacizumab (avastin) for central and hemicentral retinal vein occlusions: IBeVO study. Retina. 2007; 27(2):141-9. [PubMed: 17290194]

CVOS Group 1995. Group CVOS. Evaluation of grid pattern photocoagulation for macular edema in central vein occlusion. The Central Vein Occlusion Study Group M report. Ophthalmology. 1995; 102(10):1425-33. [PubMed: 9097788]

CVOS Group 1997. Group CVOS. Natural history and clinical management of central retinal vein occlusion. The Central Vein Occlusion Study Group. Archives of Ophthalmology. 1997; 115(10): 1275 . 
DeCroos 2009. DeCroos FC, Shuler RK Jr, Stinnett S, Fekrat S. Pars plana vitrectomy, internal limiting membrane peeling, and panretinal endophotocoagulation for macular edema secondary to central retinal vein occlusion. American Journal of Ophthalmology. 2009; 147(4):627-33. [PubMed: 19193361]

Edelman 2005. Edelman JL, Lutz D, Castro MR. Corticosteroids inhibit VEGF-induced vascular leakage in a rabbit model of blood-retinal and blood-aqueous barrier breakdown. Experimental Eye Research. 2005; 80(2):249-58. [PubMed: 15670803]

Everett 2006. Everett AI, Yang SS. Venous occlusive disease: the latest in current management. Retina. 2006; 26(6):S63-4. [PubMed: 16832302]

Eyetech 2008. Eyetech, Inc. Macugen - Pegatanib sodium injection. www.macugen.com/ macugenUSPI.pdf 2008

Funk 2009. Funk M, Kriechbaum K, Prager F, Benesch T, Georgopoulos M, Zlabinger GJ, et al. Intraocular concentrations of growth factors and cytokines in retinal vein occlusion and the effect of therapy with bevacizumab. Investigative Ophthalmology \& Visual Science. 2009; 50(3):102532. [PubMed: 19060280]

Genentech 2008. Genentech, Inc. Lucentis: Full prescribing information. www.gene.com/gene/ products/information/pdf/lucentisprescribing pdf 2008

Genentech 2009. Genentech, Inc. Avastin: Full prescribing information. www.gene.com/gene/ products/information/pdf/avastinprescribing.pdf 2009

Genetech/Roche 2009a. Genentech/Roche. Lucentis - Ranibizumab injection: Product Information Home. www.gene.com/gene/products/information/tgr/lucentis/ 2009

Genetech/Roche 2009b. Genetech/Roche. Avastin: Product Information Home. www.gene.com/gene/ products/information/oncology/avastin/2009

Gewaily 2009. Gewaily D, Greenberg PB. Intravitreal steroids versus observation for macular edema secondary to central retinal vein occlusion. Cochrane Database of Systematic Reviews. 2009; (1)10.1002/14651858.CD007324.pub2

Glanville 2006. Glanville JM, Lefebvre C, Miles JN, Camosso-Stefinovic J. How to identify randomized controlled trials in MEDLINE: ten years on. Journal of the Medical Library Association. 2006; 94(2):130-6. [PubMed: 16636704]

Gragoudas 2004. Gragoudas ES, Adamis AP, Cunningham ET, Feinsod M Jr, Guyer DR. Pegaptanib for neovascular age-related macular degeneration. New England Journal of Medicine. 2004; 351(27):2805-16. [PubMed: 15625332]

Gregori 2010. Gregori NZ, Feuer W, Rosenfeld PJ. Novel method for analyzing snellen visual acuity measurements. Retina. 2010; 30(7):1046-50. [PubMed: 20559157]

Guex-Crosier 1999. Guex-Crosier Y. The pathogenesis and clinical presentation of macular edema in inflammatory diseases. Documenta Ophthalmologica. 1999; 97(3-4):297-309. [PubMed: 10896343]

Haller 2010. Haller JA, Bandello F, Belfort R, Blumenkranz MS, Gillies M, Heier J, et al. The OZURDEX GENEVA Study Group. Randomized, sham-controlled trial of dexamethasone intravitreal implant in patients with macular edema due to retinal vein occlusion. Ophthalmology. 2010; 117(6):1134-46. [PubMed: 20417567]

Hasselbach 2007. Hasselbach HC, Ruefer F, Feltgen N, Schneider U, Bopp S, Hansen LL, et al. Treatment of central retinal vein occlusion by radial optic neurotomy in 107 cases. Graefes Archive for Clinical and Experimental Ophthalmology. 2007; 245(8):1145-56.

Hayreh 1983. Hayreh SS. Classification of central retinal vein occlusion. Ophthalmology. 1983; 90(5): 458-74. [PubMed: 6877778]

Hayreh 1990. Hayreh SS, Klugman MR, Podhajsky P, Servais GE, Perkins ES. Argon laser panretinal photocoagulation in ischemic central retinal vein occlusion. A 10-year prospective study. Graefes Archive for Clinical and Experimental Ophthalmology. 1990; 228(4):281-96.

Hayreh 1994. Hayreh SS, Zimmerman MB, Podhajsky P. Incidence of various types of retinal vein occlusion and their recurrence and demographic characteristics. American Journal of Ophthalmology. 1994; 117(4):429-41. [PubMed: 8154523] 
Hayreh 2001. Hayreh SS, Zimmerman B, McCarthy MJ, Podhajsky P. Systemic diseases associated with various types of retinal vein occlusion. American Journal of Ophthalmology. 2001; 131(1): 61-77. [PubMed: 11162981]

Hayreh 2003. Hayreh SS. Management of central retinal vein occlusion. Ophthalmologica. 2003; 217(3):167-88. [PubMed: 12660480]

Hayreh 2005. Hayreh SS. Prevalent misconceptions about acute retinal vascular occlusive disorders. Progress in Retinal and Eye Research. 2005; 24(4):493-519. [PubMed: 15845346]

Hee 1995. Hee MR, Puliafito CA, Wong C, Duker JS, Reichel E, Rutledge B, et al. Quantitative assessment of macular edema with optical coherence tomography. Archives of Ophthalmology. 1995; 113(8):1019-29. [PubMed: 7639652]

Higgins 2009. Higgins, JPT.; Altman, DG. Chapter 8: Assessing risk of bias in included studies. In: Higgins, JPT.; Green, S., editors. Cochrane Handbook for Systematic Reviews of Interventions Version 5.0.1. The Cochrane Collaboration; 2008. Available from www.cochrane-handbook.org [September 2008]

Hoeh 2009. Hoeh AE, Ach T, Schaal KB, Scheuerle AF, Dithmar S. Long-term follow-up of OCTguided bevacizumab treatment of macular edema due to retinal vein occlusion. Graefe's Archive for Clinical and Experimental Ophthalmology. 2009; 247(12):1635-41.

Homsi 2007. Homsi J, Daud AI. Spectrum of activity and mechanism of action of VEGF/PDGF inhibitors. Cancer Control. 2007; 14(3):285-94. [PubMed: 17615535]

Hsu 2007. Hsu J, Kaiser RS, Sivalingam A, Abraham P, Fineman MS, Samuel MA, et al. Intravitreal bevacizumab (avastin) in central retinal vein occlusion. Retina. 2007; 27(8):1013-9. [PubMed: 18040237]

Iturralde 2006. Iturralde D, Spaide RF, Meyerle CB, Klancnik JM, Yannuzzi LA, Fisher YL, et al. Intravitreal bevacizumab (Avastin) treatment of macular edema in central retinal vein occlusion: a short-term study. Retina. 2006; 26(3):279-84. [PubMed: 16508427]

Klein 2000. Klein R, Klein BE, Moss SE, Meuer SM. The epidemiology of retinal vein occlusion: the Beaver Dam Eye Study. Transactions of the American Ophthalmological Society. 2000; 98:13341. [PubMed: 11190017]

Klein 2008. Klein R, Moss SE, Meuer SM, Klein BE. The 15-year cumulative incidence of retinal vein occlusion: the beaver dam eye study. Archives of Ophthalmology. 2008; 126(4):513-8. [PubMed: 18413521]

Kriechbaum 2008. Kriechbaum K, Michels S, Prager F, Georgopoulos M, Funk M, Geitzenauer W, et al. Intravitreal Avastin for macular oedema secondary to retinal vein occlusion: a prospective study. British Journal of Ophthalmology. 2008; 92(4):518-22. [PubMed: 18211942]

Kriechbaum 2009. Kriechbaum K, Prager F, Geltzenauer W, Benesch T, Schutze C, Simander C, et al. Association of retinal sensitivity and morphology during antiangiogenic treatment of retinal vein occlusion over one year. Ophthalmology. 2009; 116(12):2415-21. [PubMed: 19744723]

Krohne 2008. Krohne TU, Eter N, Holz FG, Meyer CH. Intraocular pharmacokinetics of bevacizumab after a single intravitreal injection in humans. American Journal of Ophthalmology. 2008; 146(4):508-12. [PubMed: 18635152]

Los 2007. Los M, Roodhart JM, Voest EE. Target practice: lessons from phase III trials with bevacizumab and vatalanib in the treatment of advanced colorectal cancer. Oncologist. 2007; 12(4):443-50. [PubMed: 17470687]

Lynch 2007. Lynch SS, Cheng CM. Bevacizumab for neovascular ocular diseases. Annals of Pharmacotherapy. 2007; 41(4):614-25. [PubMed: 17355998]

Matsumoto 2007. Matsumoto Y, Freund KB, Peiretti E, Cooney MJ, Ferrara DC, Yannuzzi LA. Rebound macular edema following bevacizumab (Avastin) therapy for retinal venous occlusive disease. Retina. 2007; 27(4):426-31. [PubMed: 17420693]

McAllister 2010. McAllister IL, Gillies ME, Smithies LA, Rochtchina E, Harper CA, Daniell MD, et al. The Central Retinal Vein Bypass Study: a trial of laser-induced chorioretinal venous anastomosis for central retinal vein occlusion. Ophthalmology. 2010; 117(5):954-65. [PubMed: 20163872] 
McIntosh 2010. McIntosh RL, Rogers SL, Lim L, Cheung N, Wang JJ, Mitchell P, et al. Natural history of central retinal vein occlusion: an evidence-based systematic review. Ophthalmology. 2010; 117(6):1113-23. [PubMed: 20430446]

Mitchell 1996. Mitchell P, Smith W, Chang A. Prevalence and associations of retinal vein occlusion in Australia. The Blue Mountains Eye Study. Archives of Ophthalmology. 1996; 114(10):1243-7. [PubMed: 8859084]

Moschos 2008. Moschos MM, Moschos M. Intraocular bevacizumab for macular edema due to CRVO. A multifocal-ERG and OCT study. Documenta Ophthalmologica. 2008; 116(2):147-52. [PubMed: 18189152]

Nguyen 2006. Nguyen QD, Tatlipinar S, Shah SM, Haller JA, Quinlan E, Sung J, et al. Vascular endothelial growth factor is a critical stimulus for diabetic macular edema. American Journal of Ophthalmology. 2006; 142(6):961-9. [PubMed: 17046701]

Opremcak 2006. Opremcak EM, Rehmar AJ, Ridenour CD, Kurz DE. Radial optic neurotomy for central retinal vein occlusion: 117 consecutive cases. Retina. 2006; 26(3):297-305. [PubMed: 16508430]

Pai 2007. Pai SA, Shetty R, Vijayan PB, Venkatasubramaniam G, Yadav NK, Shetty BK, et al. Clinical, anatomic, and electrophysiologic evaluation following intravitreal bevacizumab for macular edema in retinal vein occlusion. American Journal of Ophthalmology. 2007; 143(3): 601-6. [PubMed: 17306753]

Park 2007. Park CH, Scott AW, Fekrat S. Effect of oral pentoxifylline on cystoid macular edema associated with central retinal vein occlusion. Retina. 2007; 27(8):1020-5. [PubMed: 18040238]

Park 2010. Park DH, Kim IT. Long-term effects of vitrectomy and internal limiting membrane peeling for macular edema secondary to central retinal vein occlusion and hemiretinal vein occlusion. Retina. 2010; 30(1):117-24. [PubMed: 19996831]

Pe'er 1995. Pe'er J, Shweiki D, Itin A, Hemo I, Gnessin H, Keshet E. Hypoxia-induced expression of vascular endothelial growth factor by retinal cells is a common factor in neovascularizing ocular diseases. Laboratory Investigation. 1995; 72(6):638-45. [PubMed: 7540233]

Pe'er 1998. Pe'er J, Folberg R, Itin A, Gnessin H, Hemo I, Keshet E. Vascular endothelial growth factor upregulation in human central retinal vein occlusion. Ophthalmology. 1998; 105(3):412-6. [PubMed: 9499769]

Pieramici 2008. Pieramici DJ, Rabena M, Castellarin AA, Nasir M, See R, Norton T, et al. Ranibizumab for the treatment of macular edema associated with perfused central retinal vein occlusions. Ophthalmology. 2008; 115(10):47-54.

Pournaras 2008. Pournaras JA, Nguyen C, Vaudaux JD, Konstantinidis L, Ambresin A, Wolfensberger T. Treatment of central retinal vein occlusionrelated macular edema with intravitreal bevacizumab (Avastin): preliminary results. Klinische Monatsblatter fur Augenheilkunde. 2008; 225(5):397-400. [PubMed: 18454380]

Prager 2009. Prager F, Michels S, Kriechbaum K. Intravitreal bevacizumab (Avastin) for macular oedema secondary to retinal vein occlusion: 12-month results of a prospective clinical trial. British Journal of Ophthalmology. 2009; 93(4):452-6. [PubMed: 19074916]

Priglinger 2007. Priglinger SG, Wolf AH, Kreutzer TC, Kook D, Hofer A, Strauss RW, et al. Intravitreal bevacizumab injections for treatment of central retinal vein occlusion: six-month results of a prospective trial. Retina. 2007; 27(8):1004-12. [PubMed: 18040236]

Prisco 2002. Prisco D, Marcucci R. Retinal vein thrombosis: risk factors, pathogenesis and therapeutic approach. Pathophysiology of Haemostasis \& Thrombosis. 2002; 32(5-6):308-11. [PubMed: 13679663]

Quinlan 1990. Quinlan PM, Elman MJ, Bhatt AK, Mardesich P, Enger C. The natural course of central retinal vein occlusion. American Journal of Ophthalmology. 1990; 110(2):118-23. [PubMed: 2378375]

Raszewska-Steglinska 2009. Raszewska-Steglinska M, Gozdek P, Cisiecki S, Michalewska Z, Michalewski J, Nawrocki J. Pars plana vitrectomy with ILM peeling for macular edema secondary to retinal vein occlusion. European Journal of Ophthalmology. 2009; 19(6):1055-62. [PubMed: 19882567] 
Rensch 2009. Rensch F, Jonas JB, Spandau UHM. Early intravitreal bevacizumab for non-ischaemic central retinal vein occlusion. Acta Ophthalmologica. 2009; 87(1):77-81. [PubMed: 18937800]

RevMan 2008. The Nordic Cochrane Centre, The Cochrane Collaboration. Review Manager (RevMan) 5.0. Copenhagen: The Nordic Cochrane Centre, The Cochrane Collaboration; 2008.

Rosenfeld 2005. Rosenfeld PJ, Fung AE, Puliafito CA. Optical coherence tomography findings after an intravitreal injection of bevacizumab (avastin) for macular edema from central retinal vein occlusion. Ophthalmic Surgery, Lasers \& Imaging. 2005; 36(4):336-9.

Rouvas 2009. Rouvas A, Petrou P, Vergados I, Pechtasides D, Liarakos V, Mitsopoulou M, et al. Intravitreal ranibizumab (Lucentis) for treatment of central retinal vein occlusion: a prospective study. Graefe's Archive for Clinical and Experimental Ophthalmology. 2009; 247(12):1609-16.

Sakamoto 2009. Sakamoto A, Tsujikawa A, Masafumi O, Yamaike N, Kotera Y, Miyamoto K, et al. Evaluation of potential visual acuity in eyes with macular oedema secondary to retinal vein occlusion. Clinical \& Experimental Ophthalmology. 2009; 37(2):208-16. [PubMed: 19426405]

Schaal 2007. Schaal KB, Hoh AE, Scheuerle A, Schutt F, Dithmar S. Bevacizumab for the treatment of macular edema secondary to retinal vein occlusion. Ophthalmologe. 2007; 104(4):285-9. [PubMed: 17372737]

SCORE 2009. Ip MS, Scott IU, VanVeldhuisen PC, Oden NL, Blodi BA, Fisher M, et al. SCORE Study Research Group. A randomized trial comparing the efficacy and safety of intravitreal triamcinolone with observation to treat vision loss associated with macular edema secondary to central retinal vein occlusion: The standard care vs corticosteroid for retinal vein occlusion (SCORE) study report 5. Archives of Ophthalmology. 2009; 127(9):1101-14. [PubMed: 19752419]

Servais 1986. Servais GE, Thompsom HS, Hayreh SS. Relative afferent pupillary defect in central retinal vein occlusion. Ophthalmology. 1986; 93(3):301-3. [PubMed: 2422618]

Shahsuvaryan 2003. Shahsuvaryan ML, Melkonyan AK. Central retinal vein occlusion risk profile: a case-control study. European Journal of Ophthalmology. 2003; 13(5):445-52. [PubMed: 12841567]

Shetty 2008. Shetty R, Pai SA, Vincent A, Shetty N, Narayana KM, Sinha B, et al. Electrophysiological and structural assessment of the central retinal following intravitreal injection of bevacizumab for treatment of macular edema. Documenta Ophthalmologica. 2008; 116(2):129-35. [PubMed: 17960440]

Shima 1996. Shima DT, Gougos A, Miller JW, Tolentino M, Robinson G, Adamis AP, et al. Cloning and mRNA expression of vascular endothelial growth factor in ischemic retinas of Macaca fascicularis. Investigative Ophthalmology \& Visual Science. 1996; 37(7):1334-40. [PubMed: 8641836]

Spaide 2009. Spaide RF, Chang LK, Klancnik JM, Yannuzzi LA, Sorenson J, Slakter JS, et al. Prospective study of intravitreal ranibizumab as a treatment for decreased visual acuity secondary to central retinal vein occlusion. American Journal of Ophthalmology. 2009; 147(2):298-306. [PubMed: 18929354]

Spandau 2006. Spanday UH, Ihloff AK, Jonas JB. Intravitreal bevacizumab treatment for macular oedema due to central retinal vein occlusion. Acta Ophthalmologica Scandinavica. 2006; 84(4): 555-6. [PubMed: 16879582]

Stahl 2007. Stahl A, Agostini H, Hansen LL, Feltgen N. Bevacizumab in retinal vein occlusion-results of a prospective case series. Graefes Archive for Clinical and Experimental Ophthalmology. 2007; 245(10):1429-36.

Vinores 1999. Vinores SA, Derevjanik NL, Ozaki H, Okamoto N, Campochiaro PA. Cellular mechanisms of blood-retinal barrier dysfunction in macular edema. Documenta Ophthalmologica. 1999; 97(3-4):217-28. [PubMed: 10896335]

Wright 2007. Wright JK, Franklin B, Zant E. Clinical case report: treatment of a central retinal vein occlusion with hyperbaric oxygen. Undersea \& Hyperbaric Medicine. 2007; 34(5):315-9. [PubMed: 18019081]

Wu 2008. Wu L, Martinez-Castellanos MA, Quiroz-Mercado H, Arevalo JF, Berrocal MH, Farah ME, et al. Twelve-month safety of intravitreal injections of bevacizumab (Avastin): results of the Pan- 
American Collaborative Retina Study Group (PACORES). Graefes Archive for Clinical and Experimental Ophthalmology. 2008; 246(1):81-7.

Wu 2010. Wu L, Fernando Arevalo J, Berrocal MH, Maia M, Roca JA, Morales-Canton V, et al. Intravitreal bevacizumab as primary treatment for macular edema secondary to central retinal vein occlusion: Results of the Pan American Collaborative Retina Study Group at 24 Months. Retina. 2010; 30(7):1002-11. [PubMed: 20616679]

Zambarakji 2005 *. Zambarakji HJ, Ghazi-Nouri S, Schadt M, Bunce C, Hykin PG, Charteris DG. Vitrectomy and radial optic neurotomy for central retinal vein occlusion: effects on visual acuity and macular anatomy. Graefes Archive for Clinical and Experimental Ophthalmology. 2005; 243(5):397-405. * Indicates the major publication for the study. 


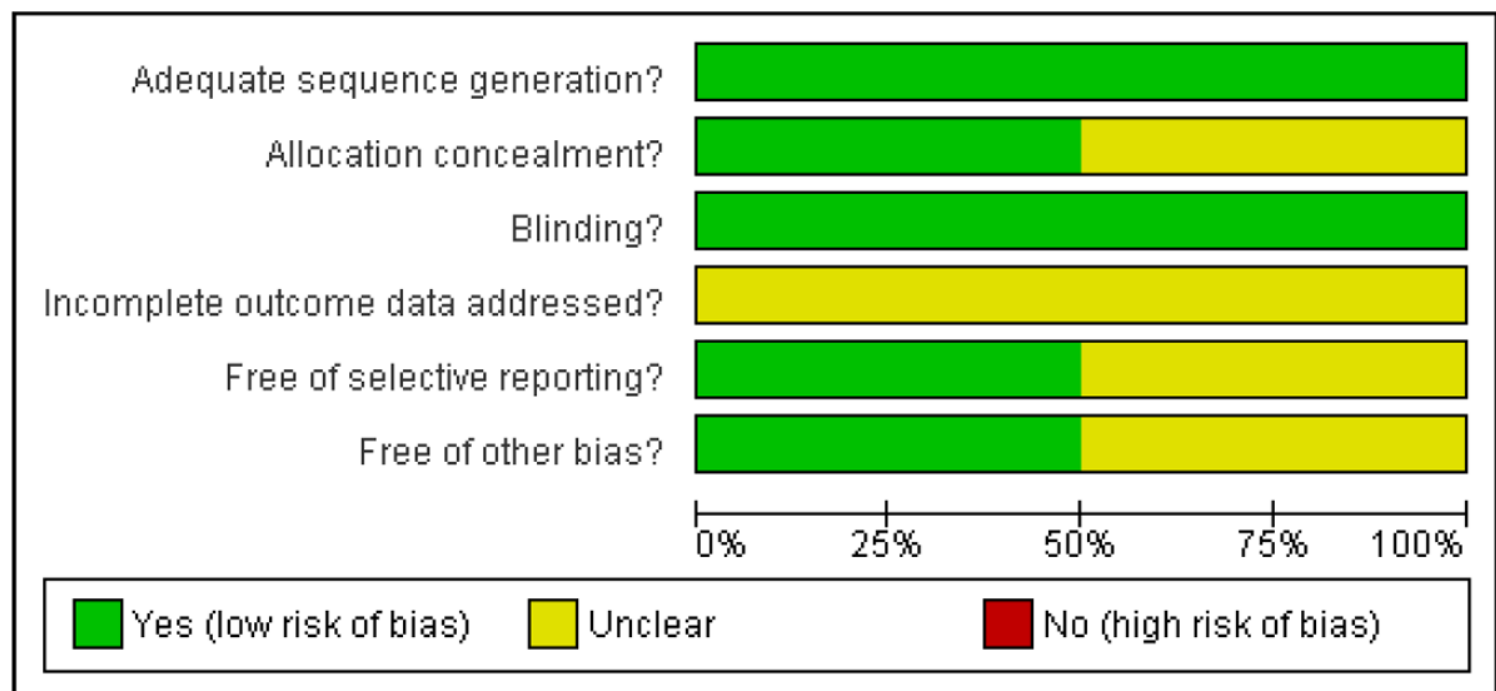

Figure 1.

Risk of bias graph: review authors' judgements about each risk of bias item presented as percentages across all included studies. 


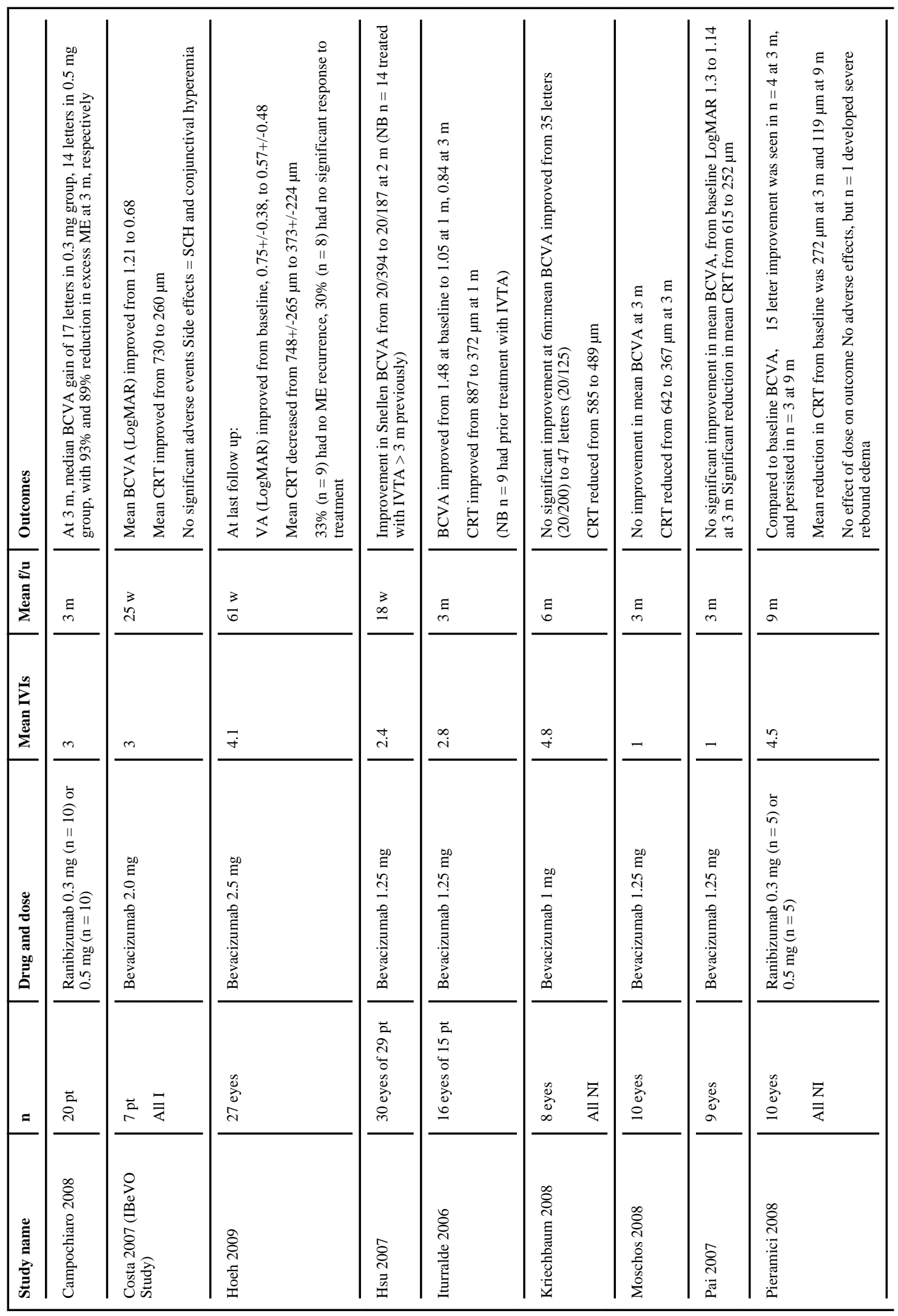

Cochrane Database Syst Rev. Author manuscript; available in PMC 2015 January 22. 


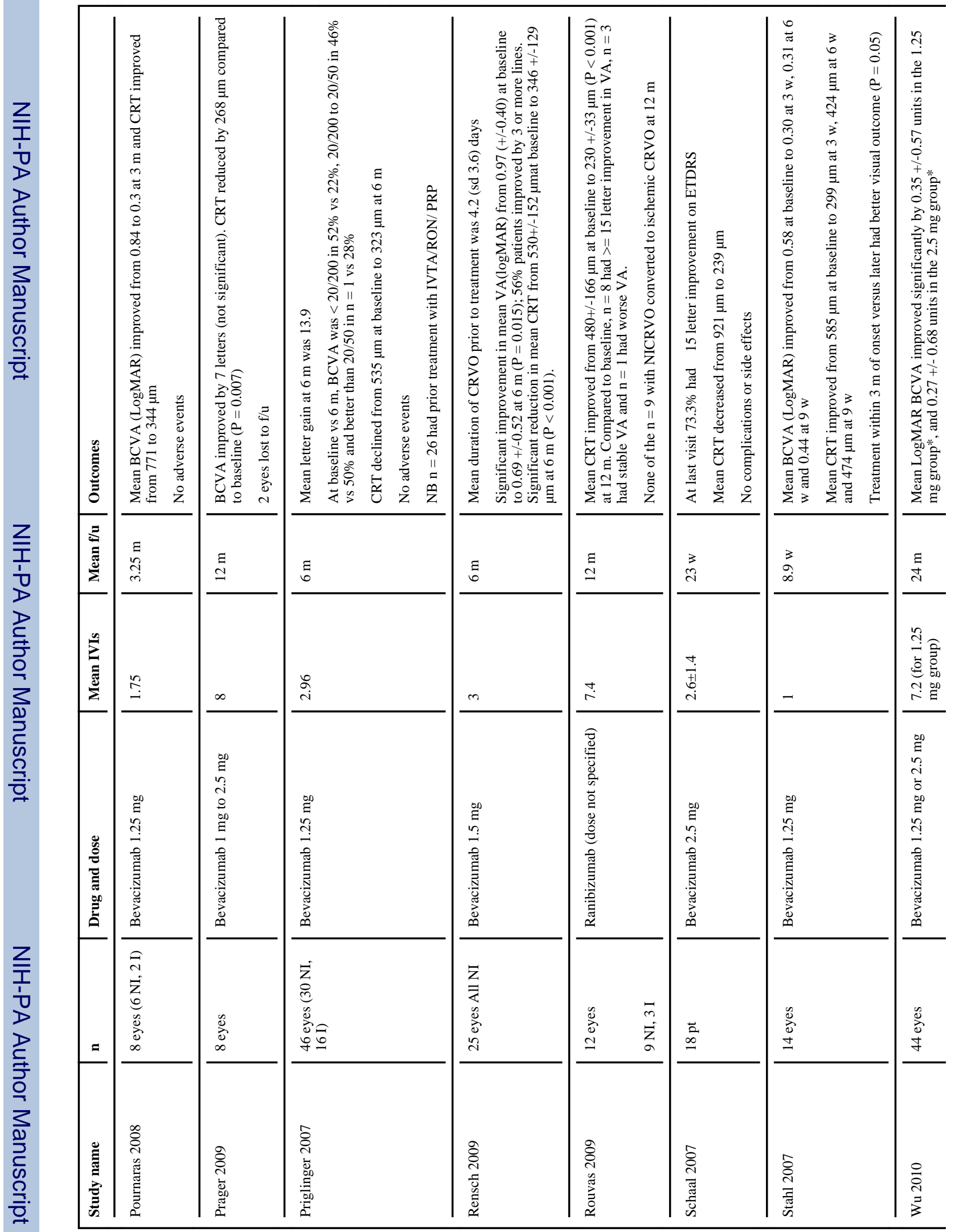



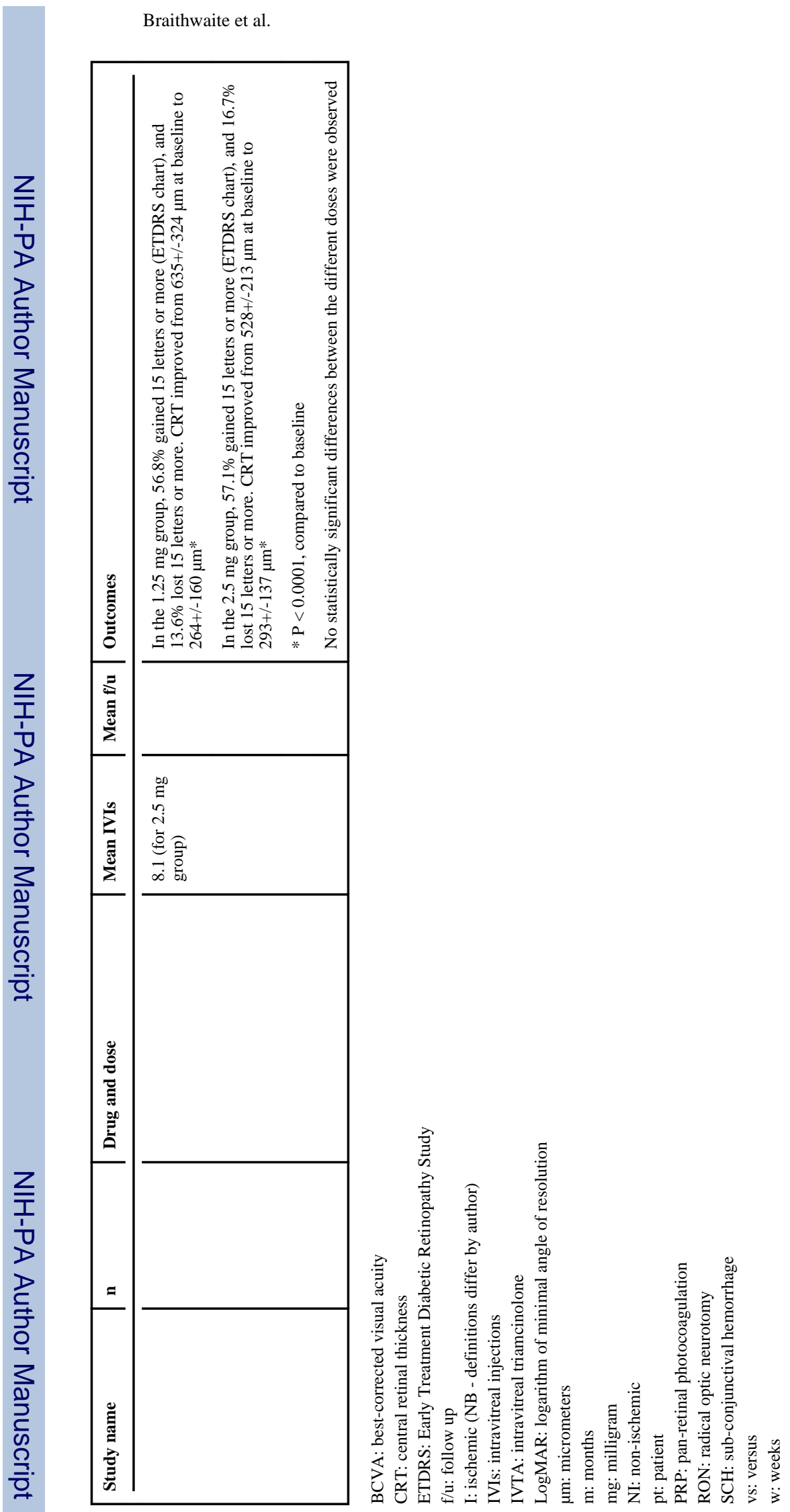

Cochrane Database Syst Rev. Author manuscript; available in PMC 2015 January 22. 
Table 2

Case reports

\begin{tabular}{|l|l|l|l|l|}
\hline Study & Patient demographics & Diagnosis and baseline & Drug and dose & Outcomes \\
\hline Matsumoto 2007 & 49 years, male & CRVO-ME & $\begin{array}{l}\text { Single bevacizumab 1.25 } \\
\mathrm{mg}\end{array}$ & $\begin{array}{l}\text { At 1 m f/u, VA 20/60, CRT 199 } \\
\mu \mathrm{m} \\
\end{array}$ \\
& VA 5/400 & $\begin{array}{l}\text { At 2 m f/u VA 20/400, CRT 1013 } \\
\mu \mathrm{m}\end{array}$ \\
\hline Spandau 2006 & 68 years, male & $\begin{array}{l}\text { Non-ischemic CRVO-ME } \\
\text { VA 20/200 } \\
\text { CRT } 662 \mu \mathrm{m}\end{array}$ & $\begin{array}{l}\text { Single bevacizumab 1.5 } \\
\mathrm{mg}\end{array}$ & $\begin{array}{l}\text { At 2 m f/u, VA 20/25, CRT 217 } \\
\mu \mathrm{m}\end{array}$ \\
\hline
\end{tabular}

CME: cystoid macular edema

CRT: central retinal thickness

CRVO: central retinal vein occlusion

f/u: follow up

ME: macular edema

mg: milligram

VA: visual acuity

m: month 


\section{Table 3}

\section{Details of other excluded non-RCTs}

\begin{tabular}{|c|c|}
\hline Study name & Study details \\
\hline Ach 2007 & $\begin{array}{l}\text { Prospective case series of bevacizumab for mixed pathologies including RVO-ME }(n=3) \text { but no data on CRVO-ME } \\
\text { specifically }\end{array}$ \\
\hline Byeon 2007 & $\begin{array}{l}\text { Retrospective case series of bevacizumab for mixed pathologies including RVO-ME, of which n }=3 \text { CRVO-ME, but no } \\
\text { data on CRVO-ME specifically }\end{array}$ \\
\hline Kriechbaum 2009 & $\begin{array}{l}\text { Prospective case series of bevacizumab for } \mathrm{n}=28 \text { patients with RVO-ME, to investigate the association between } \\
\text { functional and anatomical retinal changes using microperimetry and spectral domain OCT. Data specific to CRVO-ME } \\
\text { not reported }\end{array}$ \\
\hline Rosenfeld 2005 & Case report of bevacizumab for CRVO-ME in a patient previously treated with IVTA \\
\hline Sakamoto 2009 & $\begin{array}{l}\text { Prospective case series of bevacizumab for } n=31 \text { with RVO-ME, including } n=14 \text { with CRVO-ME. Data specific to } \\
\text { CRVO-ME not reported }\end{array}$ \\
\hline Shetty 2008 & $\begin{array}{l}\text { Prospective case series of bevacizumab for mixed etiologies of ME, of which } n=5 \text { with CRVO-ME, but no data on } \\
\text { CRVO-ME specifically }\end{array}$ \\
\hline Spaide 2009 & $\begin{array}{l}\text { Prospective case series of ranibizumab for patients with decreased visual acuity associated with CRVO (i.e. not specific to } \\
\text { patients with ME at baseline). } n=11 \text { had prior treatment with bevacizumab, and of these } n=3 \text { also had prior treatment } \\
\text { with IVTA. Data for patients with CRVO-ME at baseline and no prior treatment not reported specifically }\end{array}$ \\
\hline Wu 2008 & $\begin{array}{l}\text { Retrospective multicenter case series of bevacizumab given for different indications }(n=1173) \text {, reporting 12-month safety } \\
\text { data for combined pathologies (of which } n=66 \text { CRVO, but specific data not given) }\end{array}$ \\
\hline
\end{tabular}

CRVO: central retinal vein occlusion

IVTA: intravitreal triamcinolone

ME: macular edema

RCT: randomized controlled trial

RVO: retinal vein occlusion 
Characteristics of included studies [ordered by study ID]

\begin{tabular}{|c|c|}
\hline \multicolumn{2}{|l|}{ CRUISE 2010} \\
\hline Methods & $\begin{array}{l}\text { Study design: double-masked, randomized, sham injection-controlled trial } \\
\text { Loss to follow-up: } 2.3 \% \text { in } 0.3 \mathrm{mg} \text { group, } 8.5 \% \text { in } 0.5 \mathrm{mg} \text { group, } 11.5 \% \text { in sham group } \\
\text { Study duration: } 6 \text { months }\end{array}$ \\
\hline Participants & $\begin{array}{l}\text { Country: USA ( } 95 \text { centers) } \\
\text { Enrolment: } \mathrm{n}=392 \text { patients with non-ischemic* (except } \mathrm{n}=2 \text { with ischemic) CRVOME } \\
\text { Age: } 18 \text { and older (mean } 68 \text { years) } \\
\text { Gender: female and male (female } 43 \%, 57 \% \text { male) } \\
\text { Mean time from diagnosis to screening: } 3.3 \text { months } \\
\text { Mean study eye baseline BCVA: } 48.3 \text { letters ( 20/100 Snellen equivalent) } \\
\text { Mean baseline CFT } 685.2 \mu \mathrm{m} \\
\text { Inclusion criteria: } 18 \text { years or older; diagnosis of CRVO-ME within } 12 \text { months of study initiation; BCVA } \\
20 / 40 \text { to } 20 / 320 \text { Snellen equivalent in study eye using ETDRS chart; mean Central Retinal Thickness on } \\
2 \text { OCT scans of } 250 \mu \text { m or greater at baseline screening and on day of first treatment. } \\
\text { Exclusion criteria: prior treatment with radial optic neurotomy or sheathotomy, intraocular corticosteroid } \\
\text { use in study eye within } 3 \text { months of day } 0 \text {, intraocular anti-VEGF in study or fellow eye within } 3 \text { months } \\
\text { before day } 0 \text { or systemic anti-VEGF or pro-VEGF treatment within } 6 \text { months of day } 0 \text {; prior panretinal or } \\
\text { sectoral scatter photocoagulation within } 3 \text { months before day } 0 \text { or anticipated within } 4 \text { months after day } \\
\text { 0; laser photocoagulation for macular edema within } 4 \text { months before day } 0 \text {; prior episode of RVO; wet or } \\
\text { dry ARMD or any diabetic retinopathy; presence of a brisk relative afferent pupillary defect; CVA or MI } \\
\text { within } 3 \text { months of day } 0 \text {; more than } 10 \text { letter improvement in BCVA between screening and treatment } \\
\text { day } 0 \\
\text { * Non-ischemic CRVO defined as } \leq 10 \text { disc areas of capillary non-perfusion on FFA }\end{array}$ \\
\hline Interventions & $\begin{array}{l}\text { Intervention \#1 ( } \mathrm{n}=130): 0.5 \mathrm{mg} \text { ranibizumab every month for } 6 \text { months ( } 6 \text { injections) } \\
\text { Intervention \#2 }(\mathrm{n}=132): 0.3 \mathrm{mg} \text { ranibizumab every month for } 6 \text { months ( } 6 \text { injections) } \\
\text { Intervention \#3 (Control) }(\mathrm{n}=130) \text { : sham injection every month for } 6 \text { months ( } 6 \text { injections) } \\
\text { General instructions/treatments: all participants received topical then subconjunctival anesthetic. Sham } \\
\text { participants did not have scleral penetration; blunt pressure was applied to the globe without a needle. }\end{array}$ \\
\hline Outcomes & $\begin{array}{l}\text { Primary outcome: mean change from baseline BCVA at month } 6 \\
\text { Secondary outcomes: } 1 \text { ) Mean change from baseline BCVA over time to month } 6 ; 2 \text { ) Percentage of } \\
\text { patients who gained } 15 \text { letters or more from baseline BCVA at month } 6 ; 3 \text { ) Percentage of patients who } \\
\text { lost } 15 \text { letters or more from baseline BCVA at month } 6 ; 4 \text { ) Percentage of patients with CFT } \leq 250 \mu \text { m at } \\
\text { month } 6 ; 5 \text { ) Mean change from baseline CFT over time to month } 6 \\
\text { Exploratory efficacy outcomes included the percentage of patients with Snellen equivalent BCVA 20/200 } \\
\text { or worse at month } 6 \text {, mean change from baseline excess foveal thickness over time to month } 6 \text { (CFT } \\
\text { minus } 212 \mu \text { m), and mean change from baseline NEI VFQ-25 composite score over time to month } 6 \text {. } \\
\text { Additional outcomes included the percentage of patients with Snellen equivalent BCVA } \geq 20 / 40 \text { at } \\
\text { month } 6 \text { (an outcome generally considered sufficient to support reading and driving). Safety outcomes } \\
\text { included the incidence and severity of ocular and non-ocular adverse events and serious adverse events. } \\
\text { Measurements taken at: } \\
\text { Examination and OCT-day } 0 \text { and day } 7 \text {, months } 1 \text { to } 6 \\
\text { Patient-reported visual function assessed with the NEI VFQ-25 at day } 0 \text { and months } 1,3 \text { and } 6 \\
\text { FFA-at screening visit, prior to day } 0 \\
\text { Unit of analysis: eye } \\
\text { No economic data included }\end{array}$ \\
\hline Notes & $\begin{array}{l}\text { Study dates: July } 2007 \text { to December } 2008 \\
\text { Funding source: Genentech, Inc., South San Francisco, California }\end{array}$ \\
\hline
\end{tabular}


Publication language: English

\section{Risk of bias}

\begin{tabular}{l|l|l}
\hline Item & Authors' judgement & Description \\
\hline Adequate sequence generation? & Yes & $\begin{array}{l}\text { Quote: "patients were randomized 1:1:1". "using a dynamic randomization } \\
\text { method." } \\
\text { "Randomization was stratified by baseline BCVA letter score". "and study } \\
\text { center." }\end{array}$ \\
\hline Allocation concealment? & Unclear & $\begin{array}{l}\text { The method of allocation concealment was not described. } \\
\text { Comment: Probably done. }\end{array}$ \\
\hline
\end{tabular}

\begin{tabular}{l|l|l} 
Blinding? & Yes & $\begin{array}{l}\text { Quote: "Patients, certified BCVA examiners, and evaluating physicians were } \\
\text { masked to treatment and dose," }\end{array}$
\end{tabular}
masked to treatment and dose."

All outcomes

Quote: "Injecting physicians, who did not perform examination or outcome assessments, were masked to dose but not treatment."

\begin{tabular}{|c|c|c|}
\hline $\begin{array}{l}\text { Incomplete outcome data } \\
\text { addressed? } \\
\text { All outcomes }\end{array}$ & Unclear & $\begin{array}{l}\text { Quote: "the intent-to-treat approach was used for efficacy analyses and included } \\
\text { all patients as randomized. Missing values for efficacy outcomes were imputed } \\
\text { using the last-observation-carried-forward method" The percentage of patients } \\
\text { completing } 6 \text { months follow-up was } 97.7 \%(\mathrm{n}=129) \text { in the } 0.3 \mathrm{mg} \text { group, } \\
91.5 \%(\mathrm{n}=119) \text { in the } 0.5 \mathrm{mg} \text { treatment group, and } 88.5 \%(\mathrm{n}=115) \text { in the } \\
\text { sham group. The most common reason for withdrawal from the study was, "a } \\
\text { decision made by the physician or patient to do so." Furthermore, not all } \\
\text { participants completing the study to } 6 \text { months received all six monthly } \\
\text { injections. Specifically, } \mathrm{n}=4(3.0 \%) \text { in the } 0.3 \mathrm{mg} \text { group, } \mathrm{n}=10(7.7 \%) \text { in the } \\
0.5 \mathrm{mg} \text { group and } 16(\mathrm{n}=12.3 \%) \text { in the sham group discontinued treatment at } \\
\text { or before month } 5 \text {. This unbalanced loss to follow-up may have introduced bias } \\
\text { in the reported outcomes. }\end{array}$ \\
\hline
\end{tabular}

\begin{tabular}{l|l}
\hline Free of selective reporting? & Yes
\end{tabular}

The study protocol was accessed on ClinicalTrials.gov, and all of the study's pre-specified primary and secondary outcomes have been reported in the prespecified way.

Free of other bias?
Unclear
4 patients, 1 in the sham group and 3 in the $0.5 \mathrm{mg}$ group, were included whose time from diagnosis to screening exceeded the specified inclusion criteria of up to 12 months. The greatest duration included was 27 months, for a participant in the $0.5 \mathrm{mg}$ group.

Comment: The inclusion of outliers with a longer duration of CRVO-ME before treatment initiation is likely to reduce the apparent benefit of treatment, thus introducing a low risk of bias in the reported outcomes.

3 patients (2\%) in the $0.5 \mathrm{mg}$ group had more than 10 disc areas of capillary non-perfusion, specifically 112,113 and 109 disc areas, compared to no patients in either the sham or $0.3 \mathrm{mg}$ groups

Comment: Since these three patients were not excluded we assume that they did not have a brisk afferent pupillary defect. However, they may have had more ischemic CRVO-ME than the other participants in the trial and since all three were in the $0.5 \mathrm{mg}$ treatment group this may have introduced a bias in the outcomes.

Patients with a baseline BCVA falling outside the specified inclusion range of 20/ 40 ( 70 letters (Gregori 2010) to 20/320 ( 25 letters) were included. The number of patients with BCVA better than 20/40 or worse than 20/320, by group, cannot be determined from the data presented, although the range in BCVA (letters) was reported to be 16 to 71 letters in the sham group, 9 to 72 letters in the $0.3 \mathrm{mg}$ group and 21 to 73 letters in the $0.5 \mathrm{mg}$ group. The participants were stratified according to BCVA (in letters) of $\leq 34(\sim 20 / 200), 35$ to 54 and $\geq 55$ ( 20/80), with similar proportions of each strata in each group.

Comment: There is no reason why the range of baseline BCVAs should not be broader than that specified in the protocol, and the inclusion of participants with a poorer baseline BCVA than that pre-specified should not introduce bias, providing a similar proportion of such participants were distributed across the three groups. 
Wroblewski 2009

\begin{tabular}{l|l}
\hline Methods & $\begin{array}{l}\text { Study design: double-masked, randomized controlled trial } \\
\text { Loss to follow up: } 7 \text { withdrawals (7\%) } \\
\text { Study duration: } 30 \text { weeks }\end{array}$ \\
\hline Participants & $\begin{array}{l}\text { Country: Australia, France, Germany, Israel, Spain, United States } \\
\text { Enrolment: } 98 \text { eyes with non-ischemic CRVO-ME } \\
\text { Age: } 18 \text { and older (mean } 62.6 \text { years) }\end{array}$ \\
$\begin{array}{l}\text { Gender: female and male (46 female, } 52 \text { male) } \\
\text { Mean time from diagnosis to screening: } 77 \text { to } 82 \text { days } \\
\text { Mean study eye baseline BCVA: } 47.6 \text { to } 48.5 \text { letters (Snellen equivalent 20/100) } \\
\text { Mean baseline CFT } \mu \text { m: } 632 \text { to } 688 \mu \text { m }\end{array}$ \\
$\begin{array}{l}\text { Inclusion criteria: } 18 \text { years or older, onset of symptoms } 6 \text { months or less before baseline measurement, } \\
\text { BCVA of } 65 \text { to } 20 \text { ETDRS letters inclusive ( 20/50 to 20/400 Snellen equivalent) in study eye, BCVA of } \\
\text { better than or equal to 35 letters }(\sim 20 / 200) \text { in fellow eye, central retinal thickness of } 250 \mu \text { m or greater at } \\
\text { baseline and on day of first treatment Exclusion criteria: history of subtenon corticosteroid injection; } \\
\text { prior panretinal or sectoral scatter photocoagulation; signs of old BRVO or CRVO in study eye; other } \\
\text { retinal vascular disease; presence of a brisk relative afferent pupillary defect (an indicator for ischemic } \\
\text { CRVO); evidence of any neovascularization involving the iris, disc or retina; vitreous hemorrhage except } \\
\text { from breakthrough intraretinal hemorrhage; clinically significant concomitant ocular disease }\end{array}$
\end{tabular}

Interventions

Intervention \#1: $0.3 \mathrm{mg}$ pegaptanib sodium every 6 weeks for 24 weeks (5 injections)

Intervention \#2: $1.0 \mathrm{mg}$ pegaptanib sodium every 6 weeks for 24 weeks (5 injections)

Intervention \#3 (Control): sham injections every 6 weeks for 24 weeks (5 injections)

General instructions/treatments: all participants received injected subconjunctival anesthetic. Sham participants did not have scleral penetration; blunt pressure was applied to the globe without a needle.

\begin{tabular}{l|l}
\hline Outcomes & $\begin{array}{l}\text { Primary outcome: percentage of eyes in each group gaining 15 letters or more of visual acuity at 30 } \\
\text { weeks compared to baseline } \\
\text { Secondary outcomes: 1) Mean change in BCVA from baseline to week 30; 2) Percentage of eyes losing } \\
15 \text { or more letters of BCVA from baseline to week 30; 3) Percentage of eyes with BCVA of 35 letters or } \\
\text { more (20/200 or better) at week 30; 4) Mean change in center point and central subfield retinal thickness } \\
\text { measured by OCT at week 30 compared to baseline, and at interval assessments; 5) Percentage of eyes } \\
\text { developing retinal or iris neovascularization; 6) Incidence of ocular and systemic adverse events } \\
\text { Measurements taken at: } \\
\text { Examination - baseline (week 0) and weeks 6, 12, 18, 24, 30 } \\
\text { FFA - baseline and week 30 } \\
\text { Color photography - baseline, week 12, week 30 } \\
\text { OCT - baseline, weeks 1,3,6, 12, 18, 24, 30 } \\
\text { Unit of analysis: eye } \\
\text { No economic or QALY data included }\end{array}$ \\
\hline Notes & $\begin{array}{l}\text { Study dates: August 2004 to September 2006 } \\
\text { Item }\end{array}$ \\
\hline Adequate sequence generation? & Publication language: English \\
\hline Risk of bias & Yuthors' judgement | Description \\
\hline
\end{tabular}




\begin{tabular}{|c|c|c|}
\hline & & $\begin{array}{l}\text { Quote: "Treatment assignment was based on a dynamic minimization procedure } \\
\text { that used a stochastic treatment allocation algorithm based on the variance } \\
\text { method" }\end{array}$ \\
\hline Allocation concealment? & Yes & $\begin{array}{l}\text { Quote: "Medication kits were identified by randomization number. All kits were } \\
\text { similar in appearance, regardless of dose." } \\
\text { Quote: "The study coordinator conveyed the treatment assignment to the study } \\
\text { ophthalmologist administering the injection in a way that did not inform the } \\
\text { treating ophthalmologist or the subject" }\end{array}$ \\
\hline $\begin{array}{l}\text { Blinding? } \\
\text { All outcomes }\end{array}$ & Yes & $\begin{array}{l}\text { Participants, personnel and outcome assessors were masked. Antisepsis and } \\
\text { anesthetic procedures were the same for all participants including those } \\
\text { receiving sham. The latter group did not have scleral penetration, but blunt } \\
\text { pressure was applied to the globe without a needle to mimic penetration. } \\
\text { Quote: "The injection was not administered by the study ophthalmologist } \\
\text { responsible for patient care and assessments." }\end{array}$ \\
\hline $\begin{array}{l}\text { Incomplete outcome data } \\
\text { addressed? } \\
\text { All outcomes }\end{array}$ & Unclear & $\begin{array}{l}\text { Quote: "Efficacy analyses were conducted on the intent to treat population, } \\
\text { which included all randomized subjects. Missing data were imputed using the } \\
\text { last-observation-carried-forward method, except for repeated-measures analyses } \\
\text { of variance in which no imputation of missing data was performed" } \\
7 \text { patients withdrew from the trial ( } 3 \text { in the } 0.3 \mathrm{mg} \text { group, } 1 \text { in the } 1.0 \mathrm{mg} \text { group } \\
\text { and } 3 \text { in the sham group). The percentage of patients receiving all } 5 \text { planned } \\
\text { injections was } 81 \% \text { in the } 0.3 \mathrm{mg} \text { group, } 90 \% \text { in the } 1 \mathrm{mg} \text { treatment group, and } \\
88 \% \text { in the sham group. } \\
\text { Comment: Given the small sample size in this study, this unbalanced loss to } \\
\text { follow-up may have introduced bias in the reported outcomes. }\end{array}$ \\
\hline Free of selective reporting? & Unclear & $\begin{array}{l}\text { The study protocol was accessed on ClinicalTrials.gov, however primary and } \\
\text { secondary outcomes were not pre-specified. Both positive and negative, and } \\
\text { significant and non-significant, outcomes were reported for all } 3 \text { groups and } \\
\text { there does not appear to be any selective outcome reporting, but we cannot be } \\
\text { sure of this. }\end{array}$ \\
\hline Free of other bias? & Yes & $\begin{array}{l}\text { The mean time between occlusive event and study entry was similar between } \\
\text { groups, at } 81,82 \text { and } 77 \text { days in the } 0.3 \mathrm{mg}, 1 \mathrm{mg} \text { and sham groups, } \\
\text { respectively. Comment: We assume that all participants had a duration of less } \\
\text { than } 6 \text { months, but the range of durations since onset was not reported. }\end{array}$ \\
\hline
\end{tabular}

ARMD: age-related macular degeneration

BCVA: best-corrected visual acuity

BRVO: branch retinal vein occlusion

CFT: central foveal thickness

CRT: central retinal thickness

CRUISE: Ranibizumab for the Treatment of Macular Edema after Central Retinal Vein Occlusion Study: Evaluation of Efficacy and Safety

CRVO: central retinal vein occlusion

CVA: cerebrovascular accident

ETDRS: Early Treatment Diabetic Retinopathy Study

FFA: fluorescein fundus angiography

$\mu \mathrm{m}$ : micrometers

ME: macular edema

$\mathrm{mg}$ : milligram

MI: myocardial infarction

NEI-VFQ 25: National Eye Institute Visual Functioning Questionnaire 25 question instrument

OCT: ocular coherence tomography

PRP: pan-retinal photocoagulation

QALY: quality of life

RVO: retinal vein occlusion

VEGF: vascular endothelial growth factor

Wroblewski Study: pegaptanib sodium for macular edema secondary to central retinal vein occlusion 
Characteristics of excluded studies [ordered by study ID]

\begin{tabular}{|c|c|}
\hline Study & Reason for exclusion \\
\hline Byeon 2009 & $\begin{array}{l}\text { Randomized controlled trial comparing adjuvant topical treatment with an aqueous depressant (timolol-dorzolamide) twice } \\
\text { daily for } 9 \text { weeks, to no adjuvant treatment (control), in patients receiving a single injection of } 1.25 \mathrm{mg} \text { bevacizumab for ME } \\
\text { resulting from retinal vein occlusion, with 9-week follow up. Of } 19 \text { patients in each arm, only } 5 \text { in the adjuvant treatment group } \\
\text { and } 4 \text { in the control group had CRVO-ME, with the remainder having BRVOME. Subgroup analysis of outcomes in the CRVO- } \\
\text { ME group was not reported and the small CRVO-ME subgroup alone had insufficient power to address the null hypothesis of } \\
\text { no difference between groups in the elimination of bevacizumab, as estimated by a change in central retinal thickness on OCT, } \\
\text { at } 1,5 \text { and } 9 \text { weeks follow up. }\end{array}$ \\
\hline
\end{tabular}

BRVO: branch retinal vein occlusion

CRVO: central retinal vein occlusion

ME: macular edema

mg: milligrams

OCT: ocular coherence tomography 
Characteristics of ongoing studies [ordered by study ID]

\begin{tabular}{|c|c|}
\hline \multicolumn{2}{|l|}{ Aleris Helse Study } \\
\hline Trial name or title & A randomized study comparing ranibizumab to sham in patients with macular edema secondary to CRVO \\
\hline Methods & Double-masked randomized controlled trial (phase III) \\
\hline Participants & $\begin{array}{l}\text { Male and female patients aged } 50 \text { years and older with both ischemic and non-ischemic CRVO and VA reduction to } \\
\text { between } 6 \text { ETDRS letters (at } 1 \mathrm{~m} \text { ) and } 73 \text { letters (at } 4 \mathrm{~m} \text { ) inclusive in the study eye, for } \leq 6 \text { months with OCT- } \\
\text { confirmed ME }\end{array}$ \\
\hline Interventions & $\begin{array}{l}0.5 \mathrm{mg} \text { ranibizumab versus sham intravitreal injection given monthly for } 3 \text { months followed by reinjection if ME for a } \\
\text { total of } 6 \text { months }\end{array}$ \\
\hline Outcomes & $\begin{array}{l}\text { Primary: mean change from baseline in BCVA score at } 6 \text { months } \\
\text { Secondary: mean change from baseline in CRT and score on the NEI VFQ- } 25 \text { near activities subscale }\end{array}$ \\
\hline Starting date & March 2007 \\
\hline Contact information & Bettina Kinge, Bettina.Kinge@ retinaklinikken.no \\
\hline Notes & Completed. Results in press but not yet available \\
\hline \multicolumn{2}{|l|}{ BRAVO Study } \\
\hline Trial name or title & $\begin{array}{l}\text { Efficacy and Safety of Lucentis for Clinically Significant Macular Edema Secondary to Central Retinal Vein Occlusion } \\
\text { (BRAVO) }\end{array}$ \\
\hline Methods & Randomized, open label, controlled, two-center phase II study \\
\hline Participants & $\begin{array}{l}\text { Male and female patients aged over } 18 \text { years with CRVO and ME persisting for more than } 3 \text { months despite } \\
\text { conventional medication, with BCVA less than } 64 \text { ETDRS letters in the study eye. Patients treated previously with } \\
\text { IVTA or macular grid laser excluded. }\end{array}$ \\
\hline Interventions & $\begin{array}{l}\text { Intravitreal ranibizumab injection monthly for } 3 \text { months, with further injection if VA reduces by more than } 5 \text { letters at } \\
\text { any of the monthly follow-up visits, versus patients treated on an 'as needed' basis with argon laser PRP or macular } \\
\text { grid laser }\end{array}$ \\
\hline Outcomes & $\begin{array}{l}\text { Primary: mean change in BCVA (ETDRS chart) from baseline to } 12 \text { months } \\
\text { Secondary: change in CRT on OCT }\end{array}$ \\
\hline Starting date & August 2009 \\
\hline Contact information & Zsolt Balla, University of Pecs, Dept of Ophthalmology, Hungary. balla07@freemail.hu \\
\hline Notes & Currently recruiting patients (ClinicalTrial.Gov last checked on 18 June 2010) \\
\hline \multicolumn{2}{|l|}{ Maturi, R.K. } \\
\hline Trial name or title & $\begin{array}{l}\text { Single site, masked, randomized, controlled study to assess efficacy of Osurdex as adjunct to Avastin compared with } \\
\text { Avastin alone in the treatment of patients with macular edema secondary to central or branch retinal vein occlusion }\end{array}$ \\
\hline Methods & Masked, randomized, controlled phase IV study \\
\hline Participants & $\begin{array}{l}\text { Male and female adults aged } 18 \text { years and over with BRVO or CRVO of less than one year duration with ME }>250 \\
\text { microns on OCT and VA greater than } 24 \text { letters and less than } 80 \text { letters in the study eye }\end{array}$ \\
\hline Interventions & $\begin{array}{l}\text { Baseline } 1.25 \mathrm{mg} \text { bevacizumab intravitreal injection in both groups, with sham implant versus Osurdex } 0.7 \mathrm{mg} \text { implant. } \\
\text { Re-treatment with bevacizumab } 1.25 \mathrm{mg} \text { as required for persisting ME in both groups }\end{array}$ \\
\hline
\end{tabular}




\begin{tabular}{|c|c|}
\hline Outcomes & $\begin{array}{l}\text { Primary: visual acuity at } 6 \text { months } \\
\text { Secondary: number of injections needed over } 6 \text { months }\end{array}$ \\
\hline Starting date & March 2010 \\
\hline Contact information & Laura Bleau, eyeresearch2000@yahoo.com \\
\hline Notes & Currently recruiting patients (ClinicalTrial.Gov last checked on 18 June 2010) \\
\hline \multicolumn{2}{|l|}{$\underline{\text { Regeneron Study }}$} \\
\hline Trial name or title & $\begin{array}{l}\text { Vascular Endothelial Growth Factor (VEGF) Trap-Eye: Investigation of Efficacy and Safety in Central Retinal Vein } \\
\text { Occlusion (Regeneron 2010) }\end{array}$ \\
\hline Methods & Randomized, double-masked, controlled phase III study \\
\hline Participants & $\begin{array}{l}\text { Male and female patients aged } 18 \text { years and older with center-involved ME secondary to CRVO with mean CRT } \geq 250 \\
\text { microns on OCT, and ETDRS VA of 20/40 to 20/320 ( } 73 \text { to } 24 \text { letters) in the study eye }\end{array}$ \\
\hline Interventions & Monthly intravitreal injection of VEGF Trap-Eye $2.0 \mathrm{mg}$ versus sham injection until week 24 \\
\hline Outcomes & $\begin{array}{l}\text { Primary: improvement in VA versus baseline after } 24 \text { weeks } \\
\text { Secondary: CRT on OCT at } 24 \text { weeks }\end{array}$ \\
\hline Starting date & July 2009 \\
\hline Contact information & Robert Vitti, Regeneron Pharmaceuticals \\
\hline Notes & Currently recruiting patients (ClinicalTrial.Gov last checked on 18 June 2010) \\
\hline \multicolumn{2}{|l|}{$\underline{\text { St Erik Eye Study }}$} \\
\hline Trial name or title & Bevacizumab for Central Retinal Vein Occlusion Study (St. Eriks Eye Hospital 2009) \\
\hline Methods & Phase III randomized, double-masked, controlled clinical trial \\
\hline Participants & Male and female patients with CRVO duration less than 6 months and BCVA 20/800 to 20/50 \\
\hline Interventions & $1.25 \mathrm{mg}$ bevacizumab versus sham intravitreal injection \\
\hline Outcomes & $\begin{array}{l}\text { Primary: the proportion of patients gaining } 15 \text { ETDRS letters or more at } 6 \text { months } \\
\text { Secondary: change in CRT and cases of neovascular glaucoma at } 6 \text { months }\end{array}$ \\
\hline Starting date & May 2009 \\
\hline Contact information & David Epstein, david.epstein@ sankterik.se \\
\hline Notes & Currently recruiting patients (ClinicalTrial.Gov last checked on 18 June 2010) \\
\hline
\end{tabular}

BCVA: best-corrected visual acuity

BRVO: branch retinal vein occlusion

CRT: central retinal thickness

CRVO: central retinal vein occlusion

ETDRS: Early Treatment Diabetic Retinopathy Study

IVTA: intravitreal triamcinolone

$\mu \mathrm{m}$ : micrometers

m: meter

ME: macular edema

mg: milligram 
NEI-VFQ: National Eye Institute Visual Functioning Questionnaire

OCT: ocular coherence tomography

PRP: pan-retinal photocoagulation

VA: visual acuity

VEGF: vascular endothelial growth factor 